\title{
Presynaptic Mitochondria Volume and Abundance Increase during Development of a High-Fidelity Synapse
}

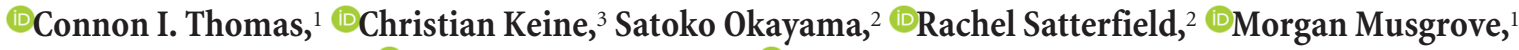 \\ Debbie Guerrero-Given, ${ }^{1}{ }^{\circledR}$ Naomi Kamasawa, ${ }^{1}$ and ${ }^{\circledR S}$ Samuel M. Young, Jr. ${ }^{3,4}$ \\ ${ }^{1}$ Electron Microscopy Core Facility, ${ }^{2}$ Molecular Mechanisms of Synaptic Function, Max Planck Florida Institute, Jupiter, Florida 33458, ${ }^{3}$ Department of \\ Anatomy and Cell Biology, Iowa Neuroscience Institute, University of Iowa, Iowa City, Iowa 52242, and ${ }^{4}$ Department of Otolaryngology, University of Iowa, \\ Iowa City, Iowa 52242
}

The calyx of Held, a large glutamatergic presynaptic terminal in the auditory brainstem undergoes developmental changes to support the high action-potential firing rates required for auditory information encoding. In addition, calyx terminals are morphologically diverse, which impacts vesicle release properties and synaptic plasticity. Mitochondria influence synaptic plasticity through calcium buffering and are crucial for providing the energy required for synaptic transmission. Therefore, it has been postulated that mitochondrial levels increase during development and contribute to the morphological-functional diversity in the mature calyx. However, the developmental profile of mitochondrial volumes and subsynaptic distribution at the calyx of Held remains unclear. To provide insight on this, we developed a helper-dependent adenoviral vector that expresses the genetically encoded peroxidase marker for mitochondria, mitoAPEX2, at the mouse calyx of Held. We developed protocols to detect labeled mitochondria for use with serial block face scanning electron microscopy to carry out semiautomated segmentation of mitochondria, high-throughput whole-terminal reconstruction, and presynaptic ultrastructure in mice of either sex. Subsequently, we measured mitochondrial volumes and subsynaptic distributions at the immature postnatal day $(\mathrm{P}) 7$ and the mature $(\mathrm{P} 21)$ calyx. We found an increase of mitochondria volumes in terminals and axons from P7 to P21 but did not observe differences between stalk and swelling subcompartments in the mature calyx. Based on these findings, we propose that mitochondrial volumes and synaptic localization developmentally increase to support high firing rates required in the initial stages of auditory information processing.

Key words: adenoviral vectors; calyx of Held; development; electron microscopy; mitochondria; synapse

Significance Statement

Elucidating the developmental processes of auditory brainstem presynaptic terminals is critical to understanding auditory information encoding. Additionally, morphological-functional diversity at these terminals is proposed to enhance coding capacity. Mitochondria provide energy for synaptic transmission and can buffer calcium, impacting synaptic plasticity; however, their developmental profile to ultimately support the energetic demands of synapses following the onset of hearing remains unknown. Therefore, we created a helper-dependent adenoviral vector with the mitochondria-targeting peroxidase mito-APEX2 and expressed it at the mouse calyx of Held. Volumetric reconstructions of serial block face electron microscopy data of immature and mature labeled calyces reveal that mitochondrial volumes are increased to support high firing rates upon maturity.

\section{Introduction}

During development of auditory brainstem circuits, many synapses undergo morphological and physiological transformations

Received Feb. 13, 2019; revised Aug. 19, 2019; accepted Aug. 22, 2019.

Author contributions: C.I.T., C.K., S.O., D.G.-G., N.K., and S.M.Y. designed research; C.I.T., C.K., S.O., R.S., M.M., D.G.-G., and N.K. performed research; C.I.T., C.K., R.S., N.K., and S.M.Y. contributed unpublished reagents/analytic tools; C.I.T., C.K., S.O., M.M., D.G.-G., N.K., and S.M.Y. analyzed data; C.I.T., C.K., D.G.-G., N.K., and S.M.Y. wrote the paper.

This work was supported by the National Institute of Deafness and Communication Disorders (R01 DC014093), the University of lowa, Max Planck Society (S.M.Y.) and a German Research Foundation postdoctoral fellowship (DFG to support the high action-potential (AP) firing rates required in the initial stages of auditory information processing ( $\mathrm{Yu}$ and Goodrich, 2014). Synaptic transmission and developmental re-
420075000 to C.K.). We thank the members of the Young laboratory for their comments on the paper, Keisuke Ohta for initial discussions, Melissa A. Ryan and Michael Morehead for help with EM volume data analysis. The authors declare no competing financial interests.

Correspondence should be addressed to Naomi Kamasawa at naomi.kamasawa@mpfi.org or Samuel M. Young Jr at samuel-m-young@uiowa.edu.

https://doi.org/10.1523/JNEUROSCI.0363-19.2019

Copyright $\odot 2019$ the authors 
modeling are energetically demanding processes (Harris et al., 2012), and mitochondria are essential organelles for supplying energy for these processes (Devine and Kittler, 2018). In addition, mitochondria play a role in calcium $\left(\mathrm{Ca}^{2+}\right)$ buffering, which can impact synaptic plasticity (Vos et al., 2010). Therefore, understanding how presynaptic mitochondria volume and distribution change with development is integral to understanding how highfidelity AP firing is achieved and maintained in the auditory brainstem.

The calyx of Held, a large glutamatergic presynaptic terminal in the medial nucleus of the trapezoid body (MNTB) in the auditory brainstem undergoes considerable morphological and physiological transformations around the onset of hearing at the end of the second postnatal week (Baydyuk et al., 2016). At the physiological level, the calyx of Held/MNTB synapse shifts from exhibiting frequent synaptic failures before hearing onset to reliable synaptic transmission at firing rates up to several hundred hertz (Taschenberger and von Gersdorff, 2000). In parallel there is a reduction in release probability $(\mathrm{Pr}$; Taschenberger and von Gersdorff, 2000; Iwasaki and Takahashi, 2001) and a shift from micro- to nano-domain release due to tighter coupling; the distance between synaptic vesicles (SVs) and voltage-gated calcium channels (VGCCs; Fedchyshyn and L. Y. Wang, 2005; L. Y. Wang et al., 2008; Chen et al., 2015). At the morphological level, the calyx transforms from cup-like to a highly fenestrated structure consisting of stalks and swellings (Kandler and Friauf, 1993; Rowland et al., 2000; Wimmer et al., 2006), and undergoes ultrastructural changes such as smaller active zones (AZs) and a reduced number of docked SVs (Taschenberger et al., 2002). Finally, the mature calyx contains mitochondria tethered to the presynaptic plasma membrane (Rowland et al., 2000; Perkins et al., 2010) and SVs are tightly packed around mitochondria (Wimmer et al., 2006).

In addition to these developmental changes, a morphologicalfunctional diversity at the mature calyx has been shown, in which calyces with many swellings have lower synaptic depression and SV release probability (Grande and L. Y. Wang, 2011). Furthermore, stalks and swellings differ in $\mathrm{Ca}^{2+}$ buffering and SV coupling states, with stalks having tighter SV coupling than swellings (Fekete et al., 2019). Nanodomain release corresponds to tight coupling with SV-VGCC distances of $\sim 25 \mathrm{~nm}$ and is considered to be energetically favorable (Eggermann et al., 2012); therefore, the energetic demands of AZs at stalks are predicted to be lower than swellings. However, the developmental changes in mitochondria volumes and subsynaptic distribution between stalks and swellings in the calyx remain unknown. To address these questions, we performed volumetric reconstructions at the electron microscopic (EM) level of calyces and mitochondria at the immature postnatal day (P)7 and mature P21 calyx. To do so, we created a helper-dependent adenoviral vector (HdAd) that expresses the mitochondrial EM marker mito-APEX2 (Martell et al., 2012, 2017; Lam et al., 2015). Because serial block face scanning EM (SBF-SEM) makes large-scale reconstructions more accessible than transmission EM (TEM; Lichtman and Denk, 2011), we developed protocols permitting identification of mitoAPEX2 with SBF-SEM and reconstructed multiple mito-APEX2positive terminals while resolving presynaptic ultrastructure. We found a developmental increase in mitochondrial volumes in the calyx and its respective axon while mitochondrial volumes were not different between stalk and swellings of the adult calyx. These data suggest that mitochondrial volumes developmentally increase to support high firing rates and may contribute to morphological-functional diversity at the calyx. Finally, because
mito-APEX2 permits identification of calyces while preserving ultrastructure, we optimized protocols using automated tapecollecting ultra-microtome (ATUM) serial section SEM (ssSEM) to analyze single-AZ ultrastructure in partially reconstructed calyces. We propose our viral vectors and methods will have broad applications for quantitative analyses of subsynaptic organization of SVs, mitochondria, and their morphological continuum using TEM, ssSEM, and SBF-SEM.

\section{Materials and Methods}

Animals. All experiments were performed in accordance with animal welfare laws and approved by the Institutional Committee for Care and Use of Animals at the Max Planck Florida Institute for Neuroscience and the University of Iowa and complied with accepted ethical best practice. Animals were housed at a $12 \mathrm{~h}$ light/dark cycle and had access to food and water ad libitum. Experiments were performed on C57BL/6J mice (RRID:IMSR_JAX:000664; The Jackson Laboratory) of either sex. Virus constructs were injected at P1 and experiments were performed at P7 (immature calyces) or P21 (functionally mature calyces).

DNA construct and recombinant viral vector production. Mito-V5APEX2 (Lam et al., 2015), a gift from Alice Ting (Addgene, plasmid \#72480; http://n2t.net/addgene:72480; RRID:Addgene_72480), was cloned into the EcoRI and NotI sites of the synapsin expression cassette. This cassette included the $470 \mathrm{bp}$ human synapsin (hsyn) promoter, the minute virus of mice (mvm) intron, and the bovine growth hormone polyA sequence (Montesinos et al., 2011). HdAd was produced as previously described (Montesinos et al., 2016). The mito V5 expression cassette was cloned into the AscI site of a modified version of pdelta 28E4, gift from Dr. Philip Ng (Department of Molecular and Human Genetics, Baylor College of Medicine, Houston, Texas), using InFusion (Clontech). This version of pdelta $28 \mathrm{E} 4$ was modified to also contain a separate neurospecific EGFP expression cassette driven by the hsyn promoter (Lübbert et al., 2017). HdAd was produced as previously described (Montesinos et al., 2016). Briefly, pHdAd mito-APEX2 hsyn EGFP was digested with PmeI and into 116 producer cells. HdAd was serially amplified in five consecutive passages. Each successive passage was performed after cytopathic effect occurred and cell lysates were subjected to three freeze/thaw cycles to lyse cells and thereby release the viral particles. HdAd was stored at $-80^{\circ} \mathrm{C}$ in storage buffer containing $10 \mathrm{~mm}$ HEPES, $250 \mathrm{~mm}$ sucrose, and $1 \mathrm{~mm} \mathrm{MgCl}_{2}$ at $\mathrm{pH}$ 7.4.

Virus injections. Virus injections at P1 were performed as described previously (Chen et al., 2013). Briefly, mice were anesthetized by hypothermia for $5 \mathrm{~min}$ in an ice bath and a stereotactic injection of $\sim 1 \mu \mathrm{l}$ of HdAd (total number of virus particles $<1 \mathrm{e} 9$ ) syn mito-V5-APEX2 syn EGFP into the cochlear nucleus was performed at a rate of $1 \mu \mathrm{l} / \mathrm{min}$ using glass pipettes (Blaubrand, IntraMARK). Following the injection, the glass needle was left in place for $1 \mathrm{~min}$ to dissipate the pressure and then slowly retracted. Animals were then placed under an infrared heat lamp and allowed to recover before being returned to their respective cages with their mother.

Acute brain slice preparation. Acute coronal brainstem slices $(200 \mu \mathrm{m})$ containing the MNTB were prepared from control and EGFP-mitoAPEX2-injected animals using a Leica VT 1200S vibratome equipped with zirconia ceramic blades (EF-INZ10, Cadence Blades) in lowcalcium artificial CSF (aCSF) solution, containing the following (in $\mathrm{mM}$ ): $125 \mathrm{NaCl}, 2.5 \mathrm{KCl}, 3 \mathrm{MgCl}_{2}, 0.1 \mathrm{CaCl}_{2}, 10$ glucose, $25 \mathrm{NaHCO}_{3}, 1.25$ $\mathrm{NaH}_{2} \mathrm{PO}_{4}, 0.4$ L-ascorbic acid, 3 myo-inositol, and $2 \mathrm{Na}$-pyruvate, $\mathrm{pH}$ 7.3-7.4. The blade was advanced at a speed of $20-50 \mu \mathrm{m} / \mathrm{s}$. Slices were immediately transferred to an incubation beaker containing standard extracellular solution (same as above but using $1 \mathrm{~mm} \mathrm{MgCl}_{2}$ and $1.2 \mathrm{mM}$ $\mathrm{CaCl}_{2}$ at $37^{\circ} \mathrm{C}$, continuously bubbled with $95 \% \mathrm{O}_{2}-5 \% \mathrm{CO}_{2}$ ). After $\sim 45$ min of incubation, slices were transferred to a recording chamber with the same saline at room temperature $\left(\sim 22^{\circ} \mathrm{C}\right)$.

Electrophysiology. Fiber stimulation was performed as described previously (Dong et al., 2018). Briefly, to record AP-evoked EPSCs, fibers of the trapezoid body were stimulated using a bipolar platinum-iridium electrode (FHC, model MX214EP) positioned medially of the MNTB. Postsynaptic MNTB neurons were whole-cell voltage clamped at 
$-73 \mathrm{mV}$ using an EPC10/2 amplifier controlled by Patchmaster software v2x90.2 (HEKA Elektronik; RRID:SCR_000034). Slices were continuously perfused with standard aCSF solution and visualized by an upright microscope (BX51WI, Olympus) through a $60 \times$ water-immersion objective (LUMPlanFL N, Olympus) and an EMCCD camera (Andor Luca $S$, Oxford Instruments). To identify calyces transduced with the EGFPmito-APEX2 virus, the slice was illuminated at an excitation wavelength of $480 \mathrm{~nm}$ using a Polychrome $\mathrm{V}$ xenon bulb monochromator (TILL Photonics). During recordings, the standard extracellular solution was supplemented with $1 \mathrm{~mm}$ kynurenic acid (Tocris Bioscience, catalog $\# 0223$ ) to avoid desensitization and saturation of postsynaptic AMPA receptors, $50 \mu \mathrm{M}$ D-AP-5 (Tocris Bioscience, catalog \#0106) to block NMDA receptors, and $20 \mu \mathrm{M}$ bicuculline (Tocris Bioscience, catalog \#0131) and $5 \mu \mathrm{M}$ strychnine (Tocris Bioscience, catalog \#2785) to block inhibitory GABA- and glycine receptors, respectively. Patch pipettes were fabricated using a PIP6 (HEKA) and had a resistance of $\sim 3-4$ $\mathrm{M} \Omega$ when filled with the following (in $\mathrm{mM}$ ): 130 Cs-gluconate, 20 tetraethylammonium-Cl, 10 HEPES, $5 \mathrm{Na}_{2}$-phosphocreatine, $4 \mathrm{MgATP}$, 0.3 NaGTP, 6 QX-314, and 5 EGTA, pH 7.2 (315 mOsm). Liquid junction potential was $13 \mathrm{mV}$ and corrected for all reported voltages. Data were acquired at a sampling rate of $50 \mathrm{kHz}$. Series resistance (3-8 M $\Omega$ ) was compensated online to $<3.0 \mathrm{M} \Omega$, and the remaining series resistance was further compensated offline to $0 \mathrm{M} \Omega$ with a time lag of $20 \mu \mathrm{s}$ (Traynelis, 1998) using a custom-written MATLAB function (MathWorks; RRID:SCR_001622).

Electrophysiological data analysis. Electrophysiological data were imported to MATLAB using a custom-modified version of sigTOOL (Lidierth, 2009) and analyzed offline with custom-written MATLAB functions. EPSC amplitudes were measured as peak amplitude minus baseline preceding the EPSC. The RRP size was calculated using the back-extrapolation method as described previously (Neher, 2015).

EM slice preparation. Slices for EM were prepared independently of acute slices for electrophysiology experiments. P7 or P21 animals previously injected with the EGFP-mito-APEX2 viral vector were anesthetized with an intraperitoneal injection of tribromoethanol $(250 \mathrm{mg} / \mathrm{kg}$ of body weight) and perfused transcardially with $0.9 \% \mathrm{NaCl}$ in $\mathrm{MilliQ}$ water, followed by a fixative containing $2 \%$ paraformaldehyde and $1-2 \%$ glutaraldehyde in $0.1 \mathrm{M}$ cacodylate buffer (CB), $\mathrm{pH} 7.4$, containing $2 \mathrm{~mm}$ $\mathrm{CaCl}_{2}$. Brains were extracted and postfixed in the same fixative for $2 \mathrm{~h}$, then washed in CB. The brainstem was sliced coronally at a thickness of $50 \mu \mathrm{m}$ (TEM, ssSEM) or $100 \mu \mathrm{m}$ (SBF-SEM) using a Leica VT $1200 \mathrm{~S}$ vibratome in $0.1 \mathrm{M} \mathrm{CB}$. The EGFP expression at the injection site and in the contralateral MNTB was confirmed under an epifluorescence microscope (CKX41, Olympus). All EM images of calyx terminals were taken from the middle region of the MNTB.

TEM sample processing and data analysis. Slices for conventional TEM imaging were reacted in a solution containing $0.05 \%$ DAB $\left(3,3^{\prime}\right.$ diaminobenzidine, Sigma-Aldrich) in $\mathrm{CB}, \mathrm{pH} 7.4$, for $1 \mathrm{~h}$ on ice. Slices were then reacted with $0.03 \% \mathrm{H}_{2} \mathrm{O}_{2}(\mathrm{v} / \mathrm{v})$ in the same well for 5-10 min and rinsed thoroughly. Labeling was confirmed using a standard brightfield microscope. Tissue was reacted with $1 \%$ aqueous osmium tetroxide for $1 \mathrm{~h}$ on ice, rinsed with distilled water, reacted with $1 \%$ aqueous uranyl acetate for $30 \mathrm{~min}$ in the dark at $4^{\circ} \mathrm{C}$, and rinsed again with distilled water. Tissue was then dehydrated in a graded ethanol series $(30,50,70,90$, $100 \%), 1: 1$ ethanol to acetone, $100 \%$ acetone, $1: 1$ acetone to propylene oxide (PO), and $100 \% \mathrm{PO}$, each $2 \times 5 \mathrm{~min}$. Tissue was infiltrated using 3:1 PO to Durcupan resin (Sigma-Aldrich) for $2 \mathrm{~h}, 1: 1 \mathrm{PO}$ to resin for $2 \mathrm{~h}$, and 1:3 PO to resin overnight, and then flat embedded in $100 \%$ resin on a glass slide and covered with an Aclar sheet at $60^{\circ} \mathrm{C}$ for $2 \mathrm{~d}$. The MNTB region contralateral to the injected cochlear nucleus was trimmed, mounted on empty resin blocks with cyanoacrylate glue (Krazy Glue, Elmer's Products), and sectioned at $40 \mathrm{~nm}$ using a Leica UC7 ultramicrotome. Sections were counterstained with uranyl acetate and lead citrate, and examined in a Tecnai G2 Spirit BioTwin transmission electron microscope (ThermoFisher Science) at $100 \mathrm{kV}$ acceleration voltage. Images were taken with a Veleta CCD camera (Olympus) operated by TIA software ( ThermoFisher Scientific). Images used for quantification were taken at $60,000 \times$ magnification. All TEM data were analyzed using Fiji imaging analysis software (Schindelin et al., 2012; RRID:
SCR_002285). Line scans were made using the plot profile function in Fiji, which was also used for ssSEM and SBF-SEM analyses. AZs were identified by the following criteria: (1) rigid opposed presynaptic and postsynaptic membrane, (2) SVs clustering at the membrane, and (3) an asymmetric postsynaptic density. AZs were measured as the presynaptic membrane opposing the postsynaptic density. Puncta adherentia (PA) were differentiated from AZs by lack of vesicles, a symmetric presynaptic and postsynaptic density, and shorter length. Vesicle distance to the AZ was calculated using a 32-bit Euclidean distance map generated from the AZ for all vesicles within $200 \mathrm{~nm}$ of the presynaptic membrane. Vesicles within $5 \mathrm{~nm}$ of the AZ were considered to be docked (Taschenberger et al., 2002; Yang et al., 2010).

Section-based immuno-electron microscopy. The samples prepared for TEM above were used for on-section immuno-electron microscopy. The MNTB region contralateral to the injected cochlear nucleus was trimmed and sectioned at $100 \mathrm{~nm}$ thickness using a Leica UC7 ultra-microtome. Sections were collected onto a 100-mesh nickel grid and air-dried. As an antigen unmasking procedure for Durcupan resin, grids were placed section side down on water heated on a hotplate to $93-95^{\circ} \mathrm{C}$ for $10 \mathrm{~min}$ (Stirling and Graff, 1995). Following heat treatment, the water was slowly cooled down for $15 \mathrm{~min}$ by mixing in room temperature water. Without drying, grids were immediately placed onto drops of blocking medium for 10 min composed of $0.1 \%$ Tween $20,1 \%$ bovine serum albumin, $1 \%$ normal goat serum, $1 \%$ fish skin gelatin, and $0.005 \%$ sodium azide diluted in Tris-buffered saline (TBS) buffer, pH 7.4. Grids were then incubated on a chicken anti-GFP primary antibody solution $(0.5 \mathrm{mg} / \mathrm{ml}$; Abcam, catalog \#ab13970; RRID:AB_300798) diluted 1:100 in the same blocking medium, and placed in a humid chamber overnight at room temperature. They were then washed and secondary antibody incubation was performed for $1 \mathrm{~h}$ at room temperature with a $12 \mathrm{~nm}$ colloidal gold donkey anti-chicken antibody (Jackson ImmunoResearch, catalog \#703205-155; RRID:AB_2340368) diluted at 1:30 in blocking medium. Grids were washed again on TBS and the reaction was stabilized by placing them on $1 \%$ glutaraldehyde in PBS for 5 min. Grids were rinsed on water and counterstained with uranyl acetate and lead citrate, and examined in a Tecnai G2 Spirit BioTwin transmission electron microscope (ThermoFisher Scientific) at $80 \mathrm{kV}$ acceleration voltage. Images were taken with a Veleta CCD camera (Olympus) operated by TIA software. Gold probe density of transduced calyces, nontransduced calyces, and principal cells was calculated by counting the number of gold particles contained within the area of each terminal or cell and dividing by that area. Raw mitochondrial intensity was calculated using Fiji by demarcating each mitochondrion within a terminal contained in a single section and calculating the mean pixel intensity across all mitochondria in the terminal.

SBF-SEM sample processing and data analysis. Fixed brain slices of 100 $\mu \mathrm{m}$ thickness were trimmed to contain a single MNTB region and reacted with $\mathrm{DAB}$ and $\mathrm{H}_{2} \mathrm{O}_{2}$ as in the previous section. The tissue pieces were incubated in an aqueous solution of $2 \%$ osmium tetroxide and $1.5 \%$ potassium ferrocyanide for $30 \mathrm{~min}$ at $4^{\circ} \mathrm{C}$ in the dark. Tissue was washed with water, which was repeated between each of the following steps. Tissue was then reacted with $0.2 \%$ tannic acid in water for $30 \mathrm{~min}$, with $1 \%$ aqueous osmium tetroxide for $30 \mathrm{~min}$, with $1 \%$ aqueous thiocarbohydrizide for $20 \mathrm{~min}$, and another treatment of $1 \%$ osmium tetroxide for $30 \mathrm{~min}$ all at room temperature, and then placed in water overnight. The following day, tissue was stained en bloc with $1 \%$ phosphotungstic acid in $25 \%$ ethanol at $50^{\circ} \mathrm{C}$ for $30 \mathrm{~min}$, then with $1 \%$ uranyl acetate in $25 \%$ ethanol for $30 \mathrm{~min}$ at $4^{\circ} \mathrm{C}$, and Walton's lead aspartate for $30 \mathrm{~min}$ at $60^{\circ} \mathrm{C}$. At P7, staining of MNTB using this protocol was optimal for imaging. At $\mathrm{P} 21$, however, staining was too intense due to massive axonal myelination, which readily recruits osmium. Therefore, ethanolic uranyl acetate staining was reduced to $10 \mathrm{~min}$, and the tannic acid and second osmification steps were omitted. Infiltration and embedding were performed as described in the previous TEM sample processing section, taking extreme care in handling the brittle samples. Because SBF-SEM requires the sample to be conductive to minimize charging during imaging, the tissue was trimmed to $1 \times 0.5 \mathrm{~mm}$ and one side was exposed using an ultramicrotome (UC7, Leica), then turned downward to be remounted to a metal pin with conductive silver epoxy (CircuitWorks, Chemtronics). The new surface was then exposed and sputter-coated with a $5 \mathrm{~nm}$ layer 
of platinum. Samples were then sectioned and imaged using 3 View and Digital Micrograph (Gatan Microscopy Suite; RRID:SCR_014492) installed on a Gemini SEM300 (Carl Zeiss Microscopy) equipped with an OnPoint BSE detector (Gatan). The detector magnification was calibrated before imaging within SmartSEM imaging software (Carl Zeiss Microscopy) and Digital Micrograph with a $500 \mathrm{~nm}$ cross line grating standard. Imaging was performed at $1.4 \mathrm{kV}$ accelerating voltage, $4.45 \mathrm{kV}$ extractor voltage, $30 \mu \mathrm{m}$ aperture, working distance of $\sim 5 \mathrm{~mm}, 0.5 \mu \mathrm{s}$ pixel dwell time, $6.5 \mathrm{~nm}$ per pixel, knife speed of $0.1-0.3 \mathrm{~mm} / \mathrm{s}$ with oscillation, and 50 or $70 \mathrm{~nm}$ section thickness. Images were captured at an original size of 12,000 by 12,000 pixels. The volume analyzed for whole-cell reconstruction at P7 was $\sim 78 \times 78 \times 52 \mu \mathrm{m}\left(3.16 \times 10^{5}\right.$ $\left.\mu \mathrm{m}^{3}\right)$; the volume analyzed for P21 was $\sim 78 \times 78 \times 79 \mu \mathrm{m}\left(4.81 \times 10^{5}\right.$ $\mu \mathrm{m}^{3}$ ), which was approximately the entire thickness remaining from the $100 \mu \mathrm{m}$ tissue slice following trimming. Serial images were aligned using Digital Micrograph software and converted to TIFF format or exported as TIFFs to TrakEM2 (RRID:SCR_008954) and aligned using ScaleInvariant Feature Transform image alignment with linear feature correspondences and rigid transformation (Lowe, 2004).

For segmentation of whole terminals, images were downsampled by a factor of four to reduce computational overhead, and only every third image was used to speed up segmentation. Aligned images were exported in TIFF format to Microscopy Image Browser (MIB; RRID:SCR_016560; Belevich et al., 2016) for semiautomated segmentation of the calyx using the watershed brush tool with interpolation. Following segmentation, interpolation was visually verified in each section. Segmentations were saved separately and then converted to a mask for mitochondrial segmentation, allowing extract features specific to the terminal. Dark features were then thresholded in $3 \mathrm{D}$ and objects in $3 \mathrm{D}$ were morphologically filtered using the statistics function until only mitochondria remained. Segmented mitochondria were smoothed and manually proofed in each section. Volume measurements for terminals and mitochondria were calculated from meshed surfaces of the segmented data, beginning at the base of the axon, identified as the location where the area of the calyx cross section began to open into the main portion of the terminal. Axon measurements were taken from the opening of the terminal to where the axon left the volume. Only calyx terminals that were fully contained within the imaged volume were analyzed, resulting in six calyces and eight minor terminals each at P7 and P21. Scale bars presented in figures are extracted from the original EM micrographs.

For full-resolution analysis of the ultrastructure of the subcompartments, one calyx at P7 (see Fig. 5D, far left) and two calyces at P21 (see Fig. 5E, far left and far right) were sampled. A P7 the calyx exists largely as a cup structure, whereas the P21 terminal can be divided into stalk and swelling subcompartments. We used the definition of stalk and swelling as defined by Wimmer et al. (2006) and Grande and L. Y. Wang (2011). An ROI measuring $6.5 \times 6.5 \times 7 \mu \mathrm{m}$ was used to sample the axons, cup, and stalks, because they are not discrete structures. Swellings could be defined as discrete cytoplasmic compartments containing AZs, SVs, and typically mitochondria, having at least one thin neck connecting it to another compartment, and therefore could be sampled as distinct structures. One axon and terminal (cup) were sampled at P7. Two axons ( 1 per calyx), four stalks ( 2 per calyx), and 22 swellings ( 16 and 6 per calyx) from two calyces were sampled at P21.

For the partial volume at P7, a series of 300 sections at native XYZ resolution ( $6.5 \mathrm{~nm}$ per pixel, $50 \mathrm{~nm}$ thick) was used to semiautomatically segment the calyx terminal and mitochondria. A complete stack of aligned TIFF images was cropped to the size of the terminal using Fiji, and then exported to MIB. Gaussian smoothing was performed on the images and the terminal was segmented using the semiautomatic graphcut segmentation function. Segmentations were proofed manually in each section.

For all reconstructions, Amira v6.5 (Amira 3D analysis; RRID: SCR_007353) was used as a measurement tool, visualization tool, and video creation tool. Blender v2.79, 2.8 (RRID:SCR_008606) was used to create $3 \mathrm{D}$ renderings of terminals.

ssSEM sample processing and data analysis. Tissue slices were processed with the same method as for TEM above. Once embedded, samples were trimmed to a $\sim 2 \times 3 \mathrm{~mm}$ rectangle, sectioned at $50 \mathrm{~nm}$ using the ATUM- tome (RMC Boeckeler), and collected on a reel of Kapton tape. Tape containing sections was attached to a 4-inch silicon wafer in rows using double sided carbon tape (EMS, catalog \#77817-50) and sections were post-stained with uranyl acetate and lead citrate. Wafers were coated with a $5 \mathrm{~nm}$ layer of carbon before imaging to limit charging (Leica, ACE600). Image acquisition was performed semiautomatically using a Merlin VP Compact SEM equipped with Atlas 5 AT software (Carl Zeiss Microscopy). Overview images of sections were acquired and registered using SE2 signal at $2 \mu \mathrm{m}$ per pixel. Medium magnification images of the general region-of-interest were acquired to identify potential synaptic terminals at $30 \mathrm{~nm}$ per pixel using a BSE detector. High-magnification images of targets were captured using an Inlens Duo detector at an accelerating voltage of $1.9 \mathrm{kV}, 4.45 \mathrm{kV}$ extractor voltage, $60 \mu \mathrm{m}$ aperture, $\sim 6.8 \mathrm{~mm}$ working distance, $\sim 12.8 \mu$ s pixel dwell time, and $5 \mathrm{~nm}$ per pixel. The detector was calibrated before imaging using a $500 \mathrm{~nm}$ cross line grating replica. Images were batch exported as TIFF files and aligned automatically using the TrakEM2 plugin using Scale-Invariant Feature Transform image alignment with linear feature correspondences and rigid transformation. MIB was used to semiautomatically segment calyx of Held terminals using the watershed brush tool. Amira was used for analysis of the $3 \mathrm{D}$ vesicle pool, vesicle docking, and extraction of $\mathrm{AZ}$ surface areas, as a visualization and video creation tool. All vesicles within a $200 \mathrm{~nm}$ distance from AZ were manually selected from the image stack, and a custom script was used to calculate the nearest distance from each vesicle to the surface of the AZ. AZ surface areas were extracted from the presynaptic side of the triangular mesh formed following reconstruction. Estimates of the total number of AZs and PA were quantified using MIB.

Controls for EM analysis. Internal controls were taken from the nontransfected MNTB ipsilateral to the injection site, or, if expression was not ubiquitous in the contralateral MNTB, individual cells identified as being negative for EGFP expression and by the lack of electron dense mitochondria (compared to nearby infected cells) were used. For postembedded samples, lack of gold particles labeling EGFP was also used to confirm a terminal was uninfected. We did not observe ipsilateral expression of EGFP or mito-APEX2 in any processed tissue by fluorescence, $\mathrm{DAB}$ reaction product, or EM dense staining at the mitochondrion. For line-scan analyses, principal neuron mitochondria were used as a staining control. For the immuno-EM study, antibody specificity was examined by omitting primary antibody from the diluent solution during the staining protocol.

Experimental design and statistical analysis. For the electrophysiological data analysis, individual neurons were considered independent samples. For immuno-TEM analysis, different cell compartments from one MNTB region (i.e., calyx terminals or principal cell bodies) were considered independent samples. For thin-section TEM analysis, AZs were considered independent samples 120 total AZs (3 animals, 40 AZs each). Data were analyzed in MATLAB v9.4 (RRID:SCR_001622), GraphPad Prism (RRID:SCR_002798), R Project for Statistical Computing v3.5.2 (RRID:SCR_001905), and JASP v0.9.2.0 (RRID:SCR_015823). Data distributions were tested for Gaussianity using the Shapiro-Wilk test. To compare two groups, a two-tailed unpaired Student's $t$ test with Welch's correction (normal distribution) or two-tailed Mann-Whitney $U$ test (non-normal distribution) were used. Immuno-TEM data groups were compared using Mood's median test. Linear regressions of total mitochondria volume to terminal volume were fit through the origin of the axes. For mitochondria volume ratio measurements of calyx terminals, a two-way repeated-measures ANOVA was conducted to compare the effects of age and compartment on volume ratio. Mitochondria diameter was compared using one-way ANOVA. $P$ values from multiple comparisons were adjusted using the Bonferroni method. Data are reported as mean \pm SEM, unless otherwise stated. For interpretation of all data, a $p$ value of 0.05 was deemed significant. $P$ values in figures are denoted ${ }^{\star} p$ $<0.05,{ }^{* *} p<0.01,{ }^{* *} p<0.001,{ }^{* * *} p<0.0001$. Because nonsignificant $p$ values do not provide evidence for the lack of effect or to draw conclusions about the probability of the null hypothesis ( $\mathrm{H} 0)$ over the alternative hypothesis (H1), we additionally calculated the Bayes factor using a Cauchy distribution with scale factor 1 as the prior distribution implemented as described previously (Rouder et al., 2009). The Bayes factor is reported as $\mathrm{BF}_{10}$ for immuno-TEM indicating the likelihood of the data 
Table 1. TEM and electrophysiology confirm EGFP-mito-APEX2 labeling with no effect on calyx of Held structure or function

\begin{tabular}{|c|c|c|c|c|c|c|c|c|c|c|c|}
\hline \multicolumn{12}{|c|}{ Immuno-TEM (Fig. 2) } \\
\hline Age & Parameter & Group & $\begin{array}{l}\text { Median } \\
\text { (1st, 3rd quartile) }\end{array}$ & Mean \pm SEM & $\begin{array}{l}n \text {; area } \\
\text { analyzed, } \mu \mathrm{m}^{2}\end{array}$ & Statistical test & $P$ & $\begin{array}{l}\text { Multiple } \\
\text { comparisons } P\end{array}$ & $\begin{array}{l}\text { Test } \\
\text { statistic }\end{array}$ & $\begin{array}{l}\text { Bayes } \\
\text { factor, } B_{10}\end{array}$ & $\eta^{2}(95 \% \mathrm{Cl})$ \\
\hline \multirow[t]{3}{*}{ P21 } & \multirow{3}{*}{$\begin{array}{l}\text { Gold particle density, } \\
\text { per } \mu \mathrm{m}^{2}\end{array}$} & Control negative terminal & $2.76(1.33,3.89)$ & $2.70 \pm 0.37$ & $19 ; 139.39$ & \multirow[t]{3}{*}{ Mood's median test } & \multirow[t]{3}{*}{0.00015} & $2.08 \mathrm{E}-5^{a}$ & \multirow[t]{3}{*}{$\chi_{2}^{2}=17.58$} & $4.8 \mathrm{E}+9^{b}$ & \multirow[t]{3}{*}{$0.84(0.80,0.90)$} \\
\hline & & Control principal cell & $3.17(2.59,4.29)$ & $3.55 \pm 0.34$ & $12 ; 285.66$ & & & $4.86 \mathrm{E}-6^{a}$ & & $2.3 \mathrm{E}+6^{b}$ & \\
\hline & & mito-APEX2 positive terminal & $13.41(11.08,19.00)$ & $14.48 \pm 1.10$ & $12 ; 142.75$ & & & & & & \\
\hline
\end{tabular}

Thin-section-TEM (Fig. 2)

\begin{tabular}{|c|c|c|c|c|c|c|c|c|c|c|}
\hline Age & Parameter & Group & Median (1st, 3rd quartile) & Mean \pm SEM & $n$ & Statistical test & $P$ & Test statistic & Bayes factor, $\mathrm{B}_{01}$ & Cohen's $U_{1}(95 \% \mathrm{Cl})$ \\
\hline \multirow[t]{3}{*}{ P21 } & AZ length, $\mu \mathrm{m}$ & Control & $263.3(229.8,315.4)$ & $283.7 \pm 7.2$ & 120 & Two-tailed MW test & 0.37 & $U=6713$ & 8.2 & $0.02(0.008,0.046)$ \\
\hline & & mito-APEX2 & $286.3(235.4,325.4)$ & $286.3 \pm 6.3$ & 120 & & & & & \\
\hline & Docked vesicles & Control & $2(1,2)$ & $1.6 \pm 0.1$ & 120 & Two-tailed MW test & 0.55 & $U=6889$ & 9.0 & $0.008(0,0.02)$ \\
\hline
\end{tabular}

Electrophysiology (Fig. 3)

\begin{tabular}{|c|c|c|c|c|c|c|c|c|c|c|}
\hline Age & Parameter & Group & $\begin{array}{l}\text { Median } \\
\text { (1st, 3rd quartile) }\end{array}$ & Mean \pm SEM & $n$ & Statistical test & $P$ & $\begin{array}{l}\text { Test } \\
\text { statistic }\end{array}$ & $\begin{array}{l}\text { Bayes } \\
\text { factor, } B_{01}\end{array}$ & $\begin{array}{l}\text { Cohen's } \\
U_{1}(95 \% \text { Cl) }\end{array}$ \\
\hline \multirow[t]{8}{*}{ P7 } & \multirow[t]{2}{*}{ Basal EPSC amplitude, $\mathrm{nA}$} & Control & $0.6(0.56,0.68)$ & $0.66 \pm 0.09$ & 10 & \multirow[t]{2}{*}{ Two-tailed MW test } & \multirow[t]{2}{*}{0.35} & \multirow[t]{2}{*}{$U=63$} & \multirow[t]{2}{*}{2.6} & \multirow[t]{2}{*}{$0.1(0.1,0.5)$} \\
\hline & & mito-APEX2 & $0.83(0.46,1.14)$ & $0.8 \pm 0.12$ & 10 & & & & & \\
\hline & \multirow[t]{2}{*}{$\mathrm{RRP}, \mathrm{nA}$} & Control & $3.52(2.9,4.4)$ & $3.71 \pm 0.33$ & 10 & \multirow[t]{2}{*}{ Two-tailed $t$ test } & \multirow[t]{2}{*}{0.76} & \multirow[t]{2}{*}{$t_{(17.9)}=0.31$} & \multirow[t]{2}{*}{3.1} & \multirow[t]{2}{*}{$0.1(0.1,0.45)$} \\
\hline & & mito-APEX2 & $3.99(3.7,4.4)$ & $3.86 \pm 0.35$ & 10 & & & & & \\
\hline & \multirow[t]{2}{*}{ Replenishment rate, $\mathrm{nAs}^{-1}$} & Control & $7.95(7.5,8.5)$ & $7.99 \pm 0.58$ & 10 & \multirow[t]{2}{*}{ Two-tailed $t$ test } & \multirow[t]{2}{*}{0.22} & \multirow[t]{2}{*}{$t_{(17.5)}=1.3$} & \multirow[t]{2}{*}{1.7} & \multirow[t]{2}{*}{$0.1(0.1,0.55)$} \\
\hline & & mito-APEX2 & $6.89(5.1,8.2)$ & $6.85 \pm 0.69$ & 10 & & & & & \\
\hline & \multirow[t]{2}{*}{$P_{\mathrm{r}}$} & Control & $0.22(0.17,0.25)$ & $0.21 \pm 0.02$ & 10 & \multirow[t]{2}{*}{ Two-tailed $t$ test } & \multirow[t]{2}{*}{0.87} & \multirow[t]{2}{*}{$t_{(17.4)}=0.16$} & \multirow[t]{2}{*}{3.2} & \multirow[t]{2}{*}{$0.15(0.1,0.45)$} \\
\hline & & mito-APEX2 & $0.22(0.15,0.29)$ & $0.21 \pm 0.03$ & 10 & & & & & \\
\hline \multirow[t]{8}{*}{ P21 } & \multirow[t]{2}{*}{ Basal EPSC amplitude, $\mathrm{nA}$} & Control & $0.7(0.49,1.4)$ & $0.94 \pm 0.23$ & 8 & \multirow[t]{2}{*}{ Two-tailed $t$ test } & \multirow[t]{2}{*}{0.43} & \multirow[t]{2}{*}{$t_{(14)}=0.56$} & \multirow[t]{2}{*}{2.3} & \multirow[t]{2}{*}{$0.125(0.125,0.5)$} \\
\hline & & mito-APEX2 & $1.24(0.42,1.81)$ & $1.26 \pm 0.31$ & 8 & & & & & \\
\hline & \multirow[t]{2}{*}{$\mathrm{RRP}, \mathrm{nA}$} & Control & $11.84(6.1,21.7)$ & $14.8 \pm 4.04$ & 8 & \multirow[t]{2}{*}{ Two-tailed MW test } & \multirow[t]{2}{*}{0.72} & $U=36$ & 2.5 & $0.1875(0.125,0.5)$ \\
\hline & & mito-APEX2 & $10.58(5.6,21.8)$ & $13.54 \pm 3.46$ & 8 & & & & & \\
\hline & Replenishment rate, $\mathrm{nAs}^{-1}$ & Control & $40.24(26.3,75.7)$ & $53.17 \pm 14.09$ & 8 & Two-tailed $t$ test & 0.71 & $t_{(13.7)}=0.38$ & 2.8 & $0.125(0.125,0.5)$ \\
\hline & & mito-APEX2 & $41.86(30.1,92.9)$ & $61.48 \pm 16.44$ & 8 & & & & & \\
\hline & $P_{r}$ & Control & $0.07(0.06,0.1)$ & $0.08 \pm 0.01$ & 8 & Two-tailed $t$ test & 0.59 & $t_{(14)}=0.56$ & 2.6 & $0.125(0.125,0.5)$ \\
\hline & & mito-APEX2 & $0.08(0.06,0.09)$ & $0.09 \pm 0.01$ & 8 & & & & & \\
\hline
\end{tabular}

$\eta^{2}$, Eta-squared, the proportion of total variation explained by the variation between groups; Cohen's $U_{1}$, the percentage of non-overlap of the two distributions, $M W=M a n n-W h i t n e y ~ U$ test.

${ }^{a}$ Bonferroni's method was used for adjustment of $p$ values for multiple comparisons of medians. P values listed under multiple comparisons are for comparisons of EGFP-mito-APEX2 terminals against control negative terminals and control principal cells, respectively.

${ }^{b}$ Bayesian ANOVA BF ${ }_{10}$ values are reported for post hoc tests of EGFP-mito-APEX2 terminals against control negative terminals and control principal cells, respectively. Note that following analyses are presented as BF ${ }_{01}$.

under $\mathrm{H} 1$ (treatment has an effect) relative to $\mathrm{H} 0$ (treatment has no effect), where values $>1$ are in favor of H1. For thin-section TEM and electrophysiology, $\mathrm{BF}_{01}$ is reported, indicating the likelihood of the data under $\mathrm{H} 0$ (treatment has no effect) relative to $\mathrm{H} 1$ (treatment has an effect), where values $>1$ are in favor of $\mathrm{H} 0$. Effect sizes were calculated using the MES toolbox in MATLAB (Hentschke and Stüttgen, 2011) and are reported as Cohen's $U_{1}$ (proportion of non-overlap of the two distributions) for two-sample comparisons and $\eta$-squared $\left(\eta^{2}\right.$; the proportion of the total variation explained by the variation between groups) for multiple-sample comparisons. Confidence intervals of effect sizes were calculated using bootstrapping with 10,000 repetitions. No statistical test was performed to predetermine sample sizes. Exact $p$ values, test statistics, Bayes factors, and effect sizes for all statistical comparisons are summarized in Table 1.

Data and software accessibility. All experimental data, movies, 3D reconstructions, and custom-written software central to the conclusion of this study are available at http://dx.doi.org/10.17632/v88r5t5myz under the terms of the Creative Commons Attribution 4.0 License (CC BY 4.0).

\section{Results}

\section{HdAd EGFP mito-APEX2 transduction leads to efficient} labeling of mitochondria at the calyx of Held

To specifically label mitochondria in the calyx we created an HdAd, which expresses mito-APEX2 and EGFP under the control of the hsyn promoter (HdAd mito-APEX2; Fig. 1A1). This dual expression allowed for identification of transduced calyces with both electron and fluorescence microscopy. Stereotactic injection of HdAd mito-APEX2 into the anteroventral cochlear nucleus (aVCN) of C57BL/6J mice was performed at $\mathrm{P} 1$ as previously described (Chen et al., 2013) and experiments were performed on P7 or P21 calyces representing the immature and mature calyx, respectively (Fig. 1A2; Borst and Soria van Hoeve, 2012). HdAd injection into the aVCN resulted in the transduction of calyces, which were identified by EGFP expression (Fig. $1 B$ ). We confirmed that these EGFP-positive terminals contained APEX2-tagged mitochondria by carrying out DAB staining, which resulted in dark reaction products in resin-embedded tissue under bright-field illumination. As expected, only the MNTB contralateral to the injection site contained $\mathrm{DAB}$ reaction products (Fig. 1C,D). At high-magnification, individual calyx terminals were visible as areas of dark deposition surrounding the somata of principal cells (Fig. $1 E, F$ ). To confirm that these electron dense precipitates were sufficient to identify mitochondria in the transduced calyx terminals, we imaged ultrathin sections using TEM. We found that presynaptic calyx terminals in both P7 and P21 samples contained electron-dense mitochondria with $\mathrm{DAB}$ precipitates accumulated in the mitochondria matrix, whereas the postsynaptic cell bodies did not (Fig. $1 G-I$ ). Additionally, labeled calyx mitochondria were easily detectable and distinguishable from unlabeled calyx mitochondria (Fig. 1J,K). This indicates that expression of mito-APEX2 using HdAd is sufficient to label mitochondria for EM applications.

\section{EGFP and mito-APEX2 dual expression does not alter presynaptic ultrastructure}

To confirm and characterize the dual expression of EGFP and mito-APEX2 we performed post-embedding immunogold labeling of EGFP on ultrathin sections from P21 calyces labeled for mito-APEX2 (Fig. 2). The cytoplasm of all calyx terminals containing electron dense mitochondria also contained gold particle 


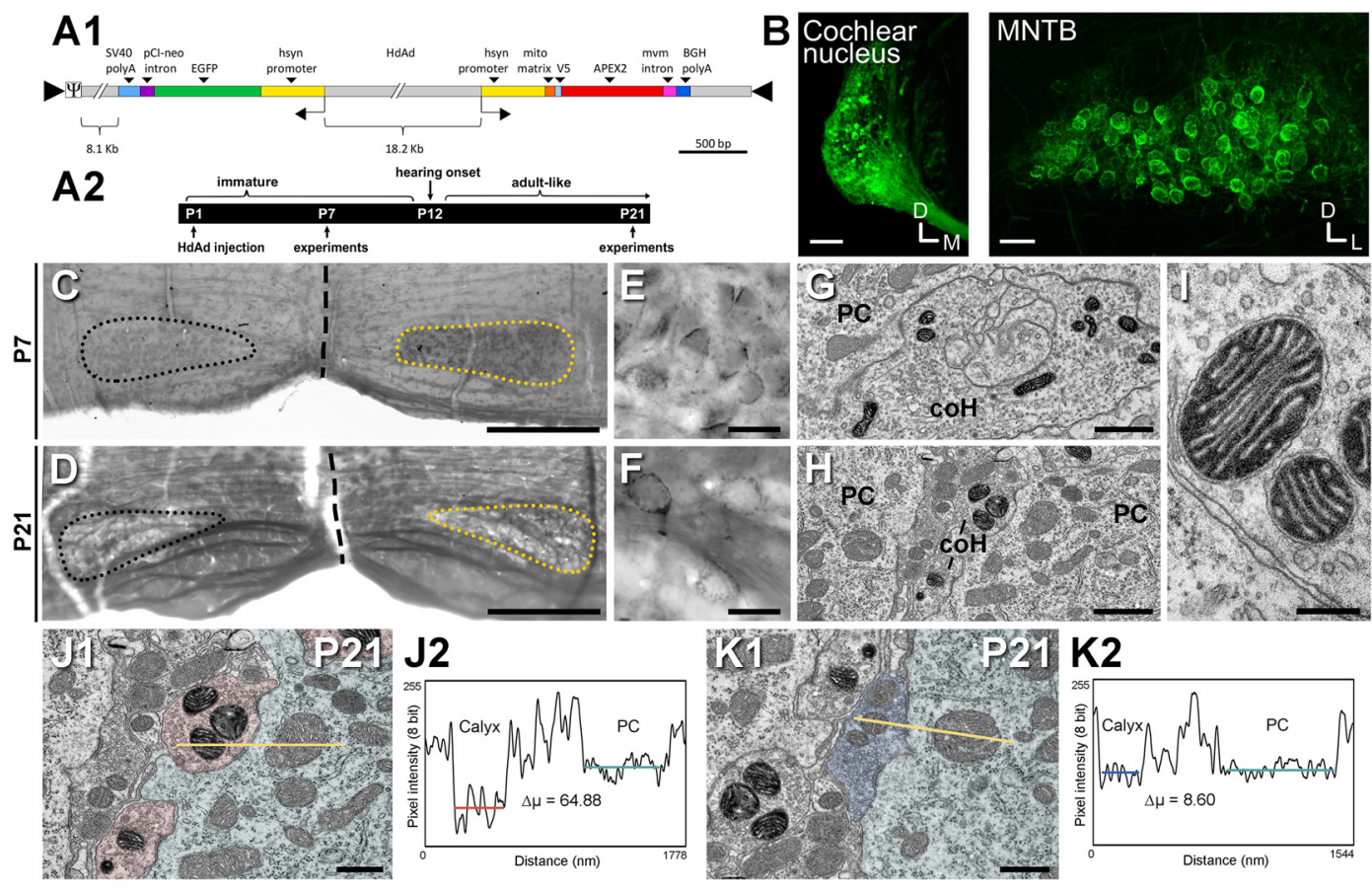

Figure 1. Expression of EGFP-mito-APEX2 at the calyx of Held presynaptic terminal. A1, Schematic of the DNA construct encoding EGFP (green) and mitochondrial matrix-targeted APEX2 (red). A2, Developmental (top) and experimental (bottom) timeline of the calyx around the onset of hearing (P12). Mito-APEX2-expressing HdAds were injected at P1 and experiments performed at either P7 or P21. B, Expression of EGFP following HdAd injection into the anteroventral cochlear nucleus resulted in green fluorescence in both the cochlear nucleus (left) and the calyx of Held terminals in the contralateral MNTB (right). Images were acquired at P21. C, D, Following DAB reaction, mito-APEX2 labeling of the contralateral MNTB was visible in embedded P7 ( () and P21 (D) tissue slices under bright-field microscope. Dashed line represents the slice midline; dotted lines demarcate the MNTB region. Yellow dotted line represents the transduced MNTB region contralateral to the injection site. $\boldsymbol{E}, \boldsymbol{F}$, High-magnification bright-field images of transduced calyx terminals from $\mathbf{C}$ and $\boldsymbol{D}$. Mito-APEX2-expressing calyces where visible by the dark area around the MNTB principal cell soma. $\mathbf{G}, \boldsymbol{H}$, Transmission electron micrographs at P7 (G) and P21 $(\boldsymbol{H})$ of transduced calyx of Held (coH) terminals showing electron-dense mitochondria in juxtaposition to mitochondria in uninfected MNTB principal cells (PCS). $I$, High-magnification image of labeled mitochondria in a transfected calyx terminal showing labeling is restricted to the matrix of the mitochondrion, whereas the intermembrane space remains unstained. J1, Transduced terminals at P21 (red) contain darker mitochondria (having higher electron density) compared with mitochondria of the opposing principal cell (aqua). $\boldsymbol{K} \mathbf{1}$, Nontransduced terminal (blue) mitochondria compared with the principal cell. $\mathbf{J} \mathbf{2}, \mathbf{K 2}$, Intensity line profiles of mitochondrial intensity in transduced and nontransduced terminals; $\Delta \mu=$ difference in mean pixel intensity between calyx and PC mitochondria. Scale bars: $\boldsymbol{B}, 200 \mu \mathrm{m}, 50 \mu \mathrm{m} ; \boldsymbol{C}, \boldsymbol{D}, 300 \mu \mathrm{m} ; \boldsymbol{E}, \boldsymbol{F}, 25 \mu \mathrm{m} ; \boldsymbol{G}, \boldsymbol{H}, 1 \mu \mathrm{m} ; \boldsymbol{I}, 200 \mathrm{~nm} ; \boldsymbol{J}, \boldsymbol{K}, 500 \mathrm{~nm}$.

labeling of EGFP (Fig. $2 A, B$ ). To quantify the expression of EGFP and mito-APEX2, we analyzed gold particle density in calyces containing labeled mitochondria compared with nontransduced calyces and principal cells (Fig. 2C). Immunogold particle density was highest in terminals containing mito-APEX2 labeled mitochondria (terminal control $=2.70 \pm 0.37$ particles $/ \mu \mathrm{m}^{2}$, principal cell control $=3.55 \pm 0.34$ particles $/ \mu \mathrm{m}^{2}$ vs EGFPmito-APEX2 $=14.48 \pm 1.10$ particles $/ \mu \mathrm{m}^{2}, p=0.00015$; Fig. $2 C$; Table 1). Although mito-APEX2 was constrained to mitochondria, we tested whether its expression affected presynaptic ultrastructure. Using ultrathin sections from P21 animals, we analyzed AZ length, SV distribution, and docked SV number (within $5 \mathrm{~nm}$ of the presynaptic membrane; Taschenberger et al., 2002) for both mito-APEX2-expressing calyces and their respective in-slice control. We observed no significant difference in any measured parameter between control and mito-APEX2expressing terminals (Fig. 2D-F; Table 1).

Mito-APEX2 expression does not alter synaptic transmission HdAd mito-APEX2 lead to efficient mitochondria labeling in the calyx and ability to visualize presynaptic ultrastructure. However, it has been shown that extreme levels of APEX expression can impact mitochondria structure (Martell et al., 2017). Because proper mitochondria function is integral for synaptic transmission and plasticity (Billups and Forsythe, 2002; Cserép et al., 2018; Lee et al., 2018), we tested whether mito-APEX2 expression impacts synaptic transmission. First, we performed afferent fiber stimulation of transduced calyces at P7 and recorded whole-cell AMPAR currents of MNTB principal cells using $50 \mathrm{~Hz}$ stimulation. We did not find evidence for altered synaptic transmission compared with age-matched WT control (Fig. 3A; Table 1). Finally, we tested whether chronic expression of HdAd mitoAPEX2 impacted synaptic transmission and repeated the experiments with P21 animals. Using afferent fiber stimulation at 300 $\mathrm{Hz}$, we found that chronic mito-APEX2 expression did not alter synaptic transmission (Fig. 3B; Table 1). These data combined with the ultrastructural measurements indicate that chronic expression of mito-APEX2 does not alter presynaptic ultrastructure or synaptic transmission.

\section{Large scale volumetric analysis of calyces and mitochondria with SBF-SEM}

Because of the large size of the calyx, volumetric analysis at finescale EM resolution of mitochondria has been restricted to partial reconstructions of single calyces using TEM (Rowland et al., 2000; Wimmer et al., 2006), ssSEM (Horstmann et al., 2012), or electron tomography (Perkins et al., 2010). Furthermore, ultrathin section-based imaging platforms are constrained by alignment issues of single sections that hamper large-scale volumetric analysis (Lichtman and Denk, 2011). In contrast, SBF-SEM requires minimal image alignment and is therefore ideal to efficiently image large EM volumes. Although SBF-SEM has been successfully used for calyx reconstructions (Holcomb et al., 2013; Xiao et al., 2013) it requires liberal application of heavy metals, 

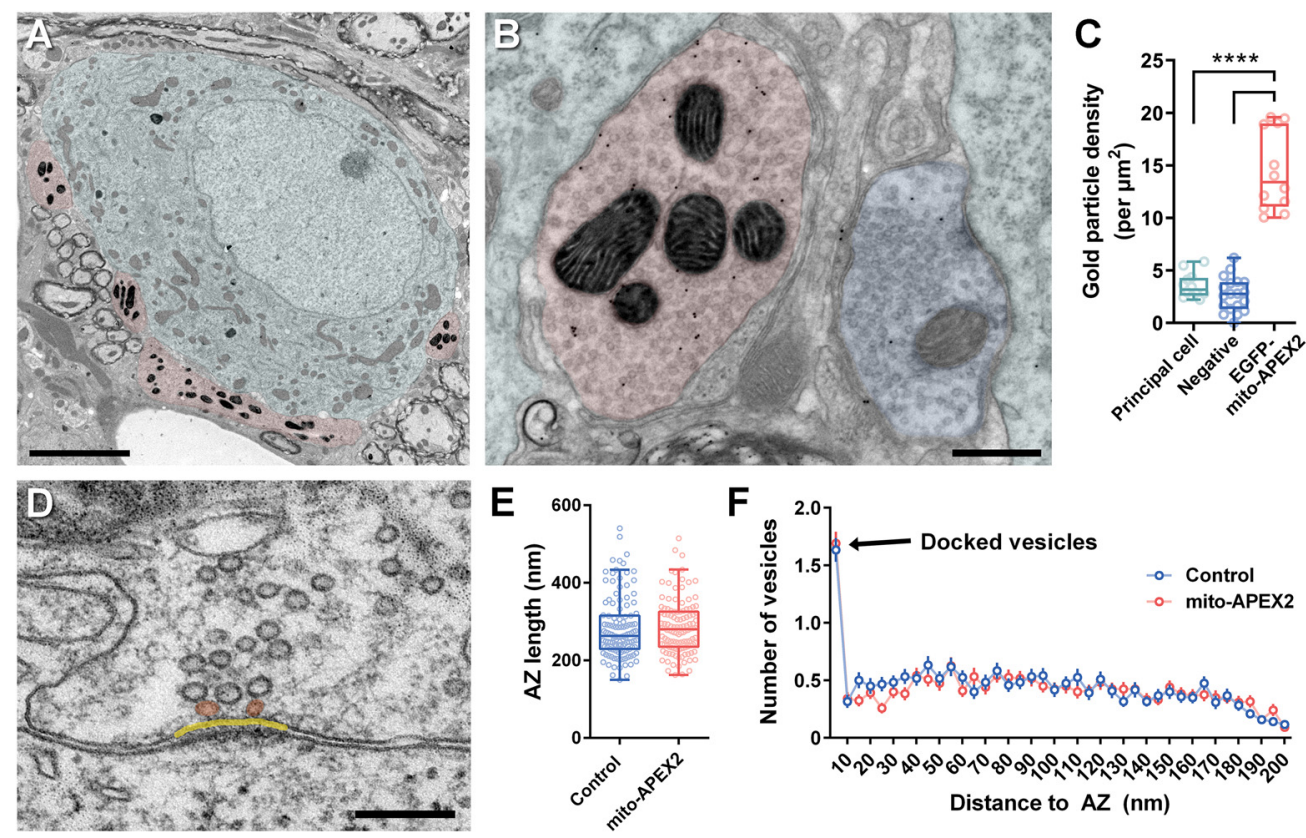

Figure 2. Double labeling of EGFP and mito-APEX2 using a combination of pre-embedding DAB-reaction labeling and post-embedding immunogold labeling. Expression of EGFP and mito-APEX2 has no effect on ultrastructure. $A$, Transduced calyx of Held terminal (red) at P21 with electron-dense mitochondria makes synaptic contact with a single principal cell (aqua). B, Comparison of a transduced calyx terminal expressing mito-APEX2 (red) versus a nontransduced control terminal (blue), both contacting separate principal cells (aqua). Gold particles (12 nm) labeling EGFP are visible within the presynaptic terminal of transduced cells. C, Gold particle density is significantly higher in calyx terminals expressing EGFP and mito-APEX2 compared with nontransduced negative terminals and principal cells. $\boldsymbol{D}$, Two docked vesicles (orange) convene at a synaptic release site. AZ is demarcated in yellow. Vesicles $<5 \mathrm{~nm}$ from the AZ were consider docked. $\boldsymbol{E}$, AZ length is unchanged between control and mito-APEX2-expressing terminals. A total of $120 \mathrm{AZs}$ from control and mito-APEX2-expressing terminals of three different animals (P21) were analyzed. $\boldsymbol{F}$, Single-section distribution of SVs up to $200 \mathrm{~nm}$ from the AZ. Box plot whiskers extend to the minimum/maximum within 1.5 interquartile range; open circles indicate individual observations. Scale bars: $A, 5 \mu \mathrm{m} ; \boldsymbol{B}, 500 \mathrm{~nm} ; \boldsymbol{D}, 200 \mathrm{~nm} ;{ }^{* * *} p<0.0001$.

which may prevent detection of mito-APEX2 labeling. To test this, we used the 3View with OnPoint BSE detector and optimized the imaging conditions (see Materials and Methods) to confirm that mito-APEX2 labeled mitochondria could be distinguished in both P7 and P21 (Fig. 4). We found calyx terminals containing mito-APEX2-positive mitochondria were clearly identifiable in both P7 and P21 samples as the electron density of labeled mitochondria in the calyx terminal was considerably higher than that of unlabeled mitochondria in the principal cell (Fig. $4 E, F$ ). Although we could visualize SVs at this resolution, identification of AZs (using the postsynaptic density as a reference) and PAs was difficult because of the lower signal-to-noise ratio of images acquired with short dwell times (Fig. 4B,D).

Subsequently, we acquired and analyzed volumes of $78 \times$ $78 \times 52 \mu \mathrm{m}$ (P7; Fig. $5 A$ ) and $78 \times 78 \times 79 \mu \mathrm{m}($ P21; Fig. $5 B)$ at an XY pixel size of $6.5 \mathrm{~nm}$ and section thickness of $70 \mathrm{~nm}$. We found that a pixel dwell time of $0.5 \mu$ s provided sufficient image quality for tracing membranes while reducing imaging time, which allowed us to collect the full volume in $\sim 30 \mathrm{~h}$ per sample. We segmented individual positive calyx terminals that were within the bounds of the datasets and performed whole-terminal reconstructions. To increase segmentation throughput and minimize dataset size, images were downsampled and every third image was used. In the acquired image volume, all six calyx terminals containing mito-APEX2-positive mitochondria plus eight labeled minor inputs were segmented at P7 in $\sim 40$ working hours. Because of the complex calyx structure in P21 animals, segmentation of six terminals and eight labeled minor inputs required $\sim 100$ working hours. In those volume datasets, the reconstructed terminals at P7 and P21 showed clear morphological differences as previously described (Sätzler et al., 2002; Taschenberger et al., 2002; Wimmer et al., 2006; Grande and L. Y. Wang,
2011; Horstmann et al., 2012; Holcomb et al., 2013; Fig. $5 A, B, D, E$; Movies 1 and 2). At P7, several filopodial extensions branched off from the cup-like terminal (Fig. 5D). These cups were thin and sheet-like, whereas terminals at P21 were composed of mainly thick, bulbous compartments without filopodial extensions (Fig. 5E). We measured the volume of individual calyx terminals containing mito-APEX2-positive mitochondria and found that calyx volumes at P21 were larger than at P7 (1307 \pm $124 \mu \mathrm{m}^{3}$ vs $841.2 \pm 136.1 \mu \mathrm{m}^{3}, p=0.03$; Table 2; Fig. $\left.5 C\right)$. The terminals at P7 had volumes between 9 and $1171 \mu \mathrm{m}^{3}$ and 5 of the 6 MNTB principal neurons were contacted by a large calyx presynaptic terminal $\left(>700 \mu \mathrm{m}^{3}\right)$ with minor terminals, although one principal neuron had a dominant, but smaller calyx terminal of $\sim 250 \mu \mathrm{m}^{3}$ and multiple minor terminals $(<100$ $\mu \mathrm{m}^{3}$; Fig. $5 A, D$, yellow terminals; Movie 1). Consistent with our data, principal cells with small dominant calyx and multiple minor competing terminals are rare at P7, comprising only $\sim 20 \%$ of cells (Holcomb et al., 2013).

At P21, terminals ranged from 10 to $1620 \mu \mathrm{m}^{3}$. We found that all (6/6) principal cells at this age were contacted by a single dominant calyx similar to previous reports (Holcomb et al., 2013) and exhibited a markedly different structure with variable degrees of fenestration as described previously (Grande and L. Y. Wang, 2011; T. Wang et al., 2015; Figure 5E; Movie 2). In addition, half of those principal cells (3/6) had mito-APEX2 labeled minor terminals (Fig. 5E; Table 2), with morphologies similar to "migratory calycigenic axons" in the young opossum (Morest, 1968) and calyceal collaterals in rodents (Rodríguez-Contreras et al., 2006). Notably, one principal cell had a moderately sized terminal $\left(272 \mu \mathrm{m}^{3}\right)$ in addition to minor terminals (Fig. $5 B, E$, green terminals). Therefore, we conclude that even though principal cells are innervated by a dominant calyx, minor terminals 


\section{P7 (50 Hz stimulation)}
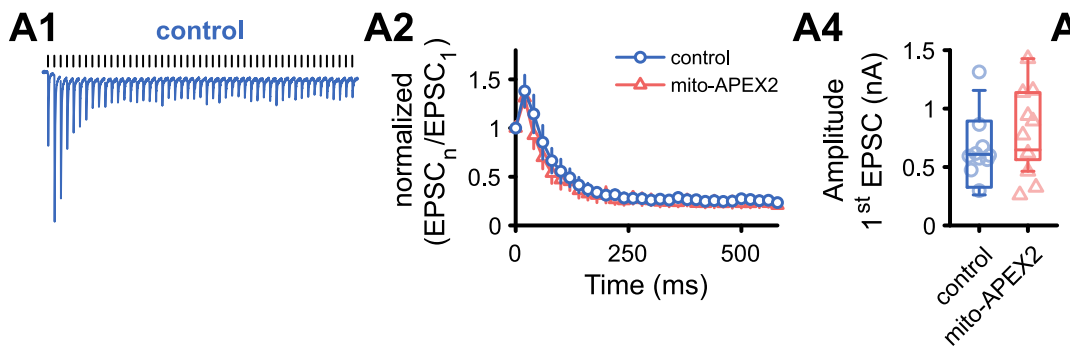

A5

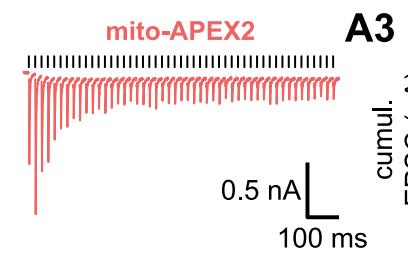

A3

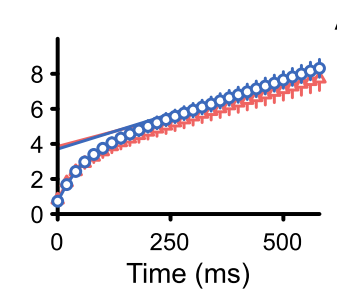

A6
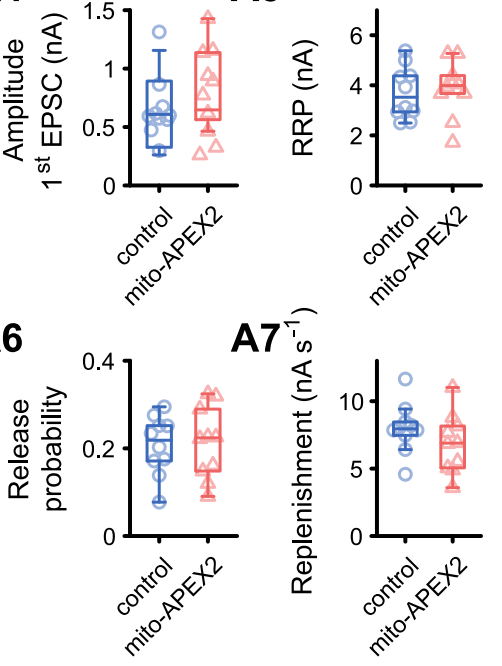

\section{P21 (300 Hz stimulation)}

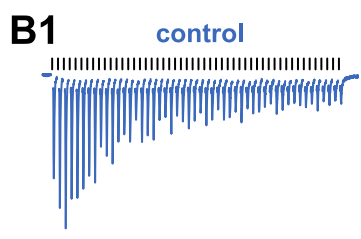

B2

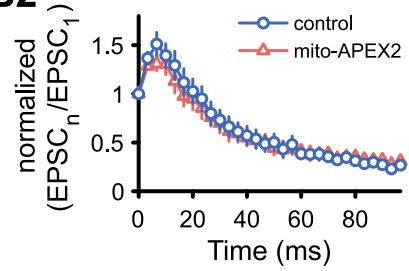

B4

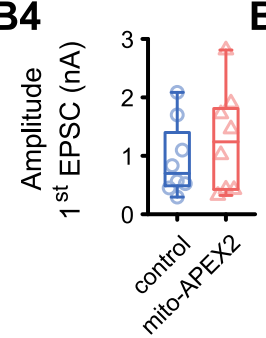

B5

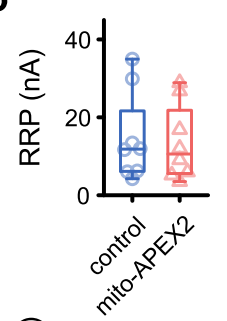

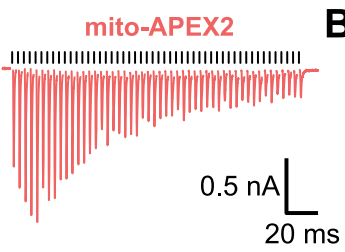

B3

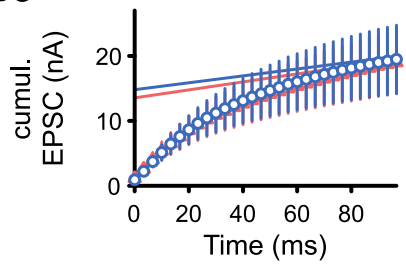

B6

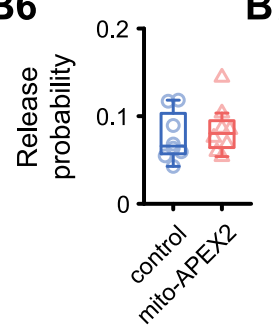

7 in

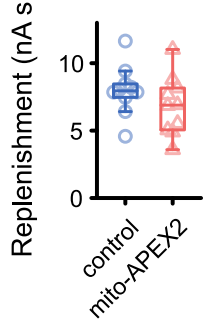

B7

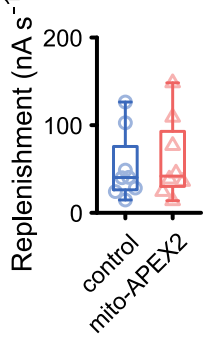

Figure 3. Expression of mito-APEX2 does not affect synaptic transmission at the calyx of Held-MNTB synapse. Synaptic transmission at the calyX of Held after expression of mito-APEX2 (red) was investigated at P7 (A) and P21 (B) and compared with age-matched wild-type control (blue). $\boldsymbol{A}$ 1, Representative traces of evoked EPSCs during afferent fiber stimulation (50 Hz) at P7 for control and mito-APEX2-transduced calyces (injected at P1). Stimulus artifacts are blanked. Vertical black lines above the traces indicate time points of fiber stimulation. A2, Averaged EPSC amplitudes normalized to the first EPSC showed comparable short-term plasticity between control and mito-APEX2-transduced calyces. A3, Cumulative EPSC amplitudes to determine the readily releasable pool (RRP) by back-extrapolating the linear fit of the last 10 data points; the $y$-intercept is an estimate of the RRP size. A4-A7, No differences between control and mito-APEX2-transduced calyces were detected regarding EPSC amplitude (A4), RRP size (A5), release probability (A6), or replenishment rate (A7). $\boldsymbol{B}$, Same layout as in $\boldsymbol{A}$. Afferent fiber stimulation was performed at $300 \mathrm{~Hz}$. Following chronic expression (20 d) of mito-APEX2, the calyx of Held-MNTB synapse showed normal synaptic transmission and no change in EPSC amplitude (BB), RRP (B5), release probability (B6), or replenishment rate (B7). Box plot whiskers extend to the minimum/maximum within 1.5 interquartile range; open symbols indicate individual cells.

still exist in the functionally mature stage of development, which might be comprised by calyceal collaterals. Finally, in addition to the labeled minor terminals, numerous small, unlabeled terminals contacted the same principal neurons at both ages but were not segmented or analyzed. These terminals may compose additional excitatory or inhibitory inputs to the MNTB principal cell that do not originate from the cochlear nucleus (Hamann et al., 2003; Awatramani et al., 2004; Albrecht et al., 2014).

\section{Mitochondrial volume ratios are higher in the mature calyx and axon than the immature calyx}

Because the high-contrast mitochondria could be easily extracted using thresholding techniques, we performed high-resolution whole-terminal mitochondria reconstructions at P7 and P21 us- ing the same volume datasets acquired with SBF-SEM. After downsampling the volume data and using every third image, whole-terminal mitochondrial volume reconstructions could be completed and proofed in several hours per terminal (Fig. $6 A-D$; Table 2; Movies 3 and 4). Because at both developmental stages, principal cells had labeled minor terminals, we separately analyzed mitochondrial volume in the calyx terminal and the minor terminals. Mitochondrial volumes scaled linearly with terminal volume at both developmental time points. However, we found that the scaling of mitochondria to calyx volume is steeper at P21 than at P7 (slope $=0.2022, R^{2}=0.95$ vs $0.0737, R^{2}=0.82$; Fig. $6 E)$. Comparison of the mitochondria to volume ratio of the terminal revealed that $20 \%$ of the P21 calyx volume is composed of mitochondria, whereas at P7 mitochondria only take up $7.8 \%$ 

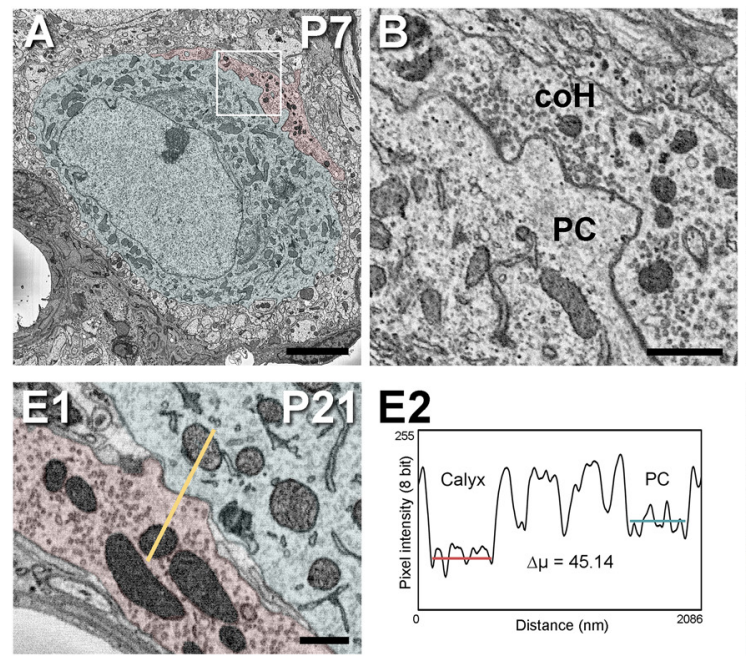
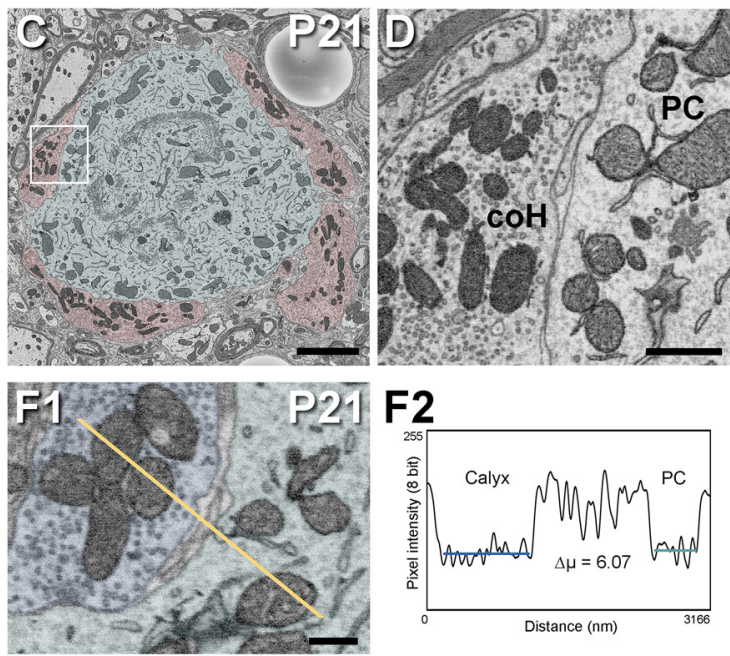

F2

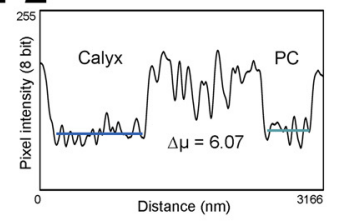

Figure 4. Mito-APEX2 labeling visualized by SBF-SEM at P7 $(\boldsymbol{A}, \boldsymbol{B})$ and P21 $(\boldsymbol{C}, \boldsymbol{D}, \boldsymbol{E}$ 1) allows for identification of transduced calyx of Held terminals. $A, C$, Block face images show the calyx of Held ( $\mathrm{COH}$; red) contacting to an MNTB principal cell (PC; aqua). $\boldsymbol{B}, \boldsymbol{D}$, High-magnification image of the white squared area in $\boldsymbol{A}$ and $\boldsymbol{C}$, respectively, showing electron-dense mitochondria in the calyx of Held terminal. E1, Transduced terminals contain darker mitochondria compared with mitochondria of the opposing principal cell. F1, Nontransduced terminal mitochondria compared with the principal cell mitochondria. $E 2, F 2$, Intensity line profiles of mitochondrial intensity in transduced and nontransduced terminals; $\Delta \mu=$ difference in mean pixel intensity between calyx and $P C$ mitochondria, respectively. Scale bars: $A, C, 5 \mu \mathrm{m} ; \boldsymbol{B}, \boldsymbol{D}, 1 \mu \mathrm{m} ; \boldsymbol{E 1}, \boldsymbol{F 1}, 500 \mathrm{~nm}$.
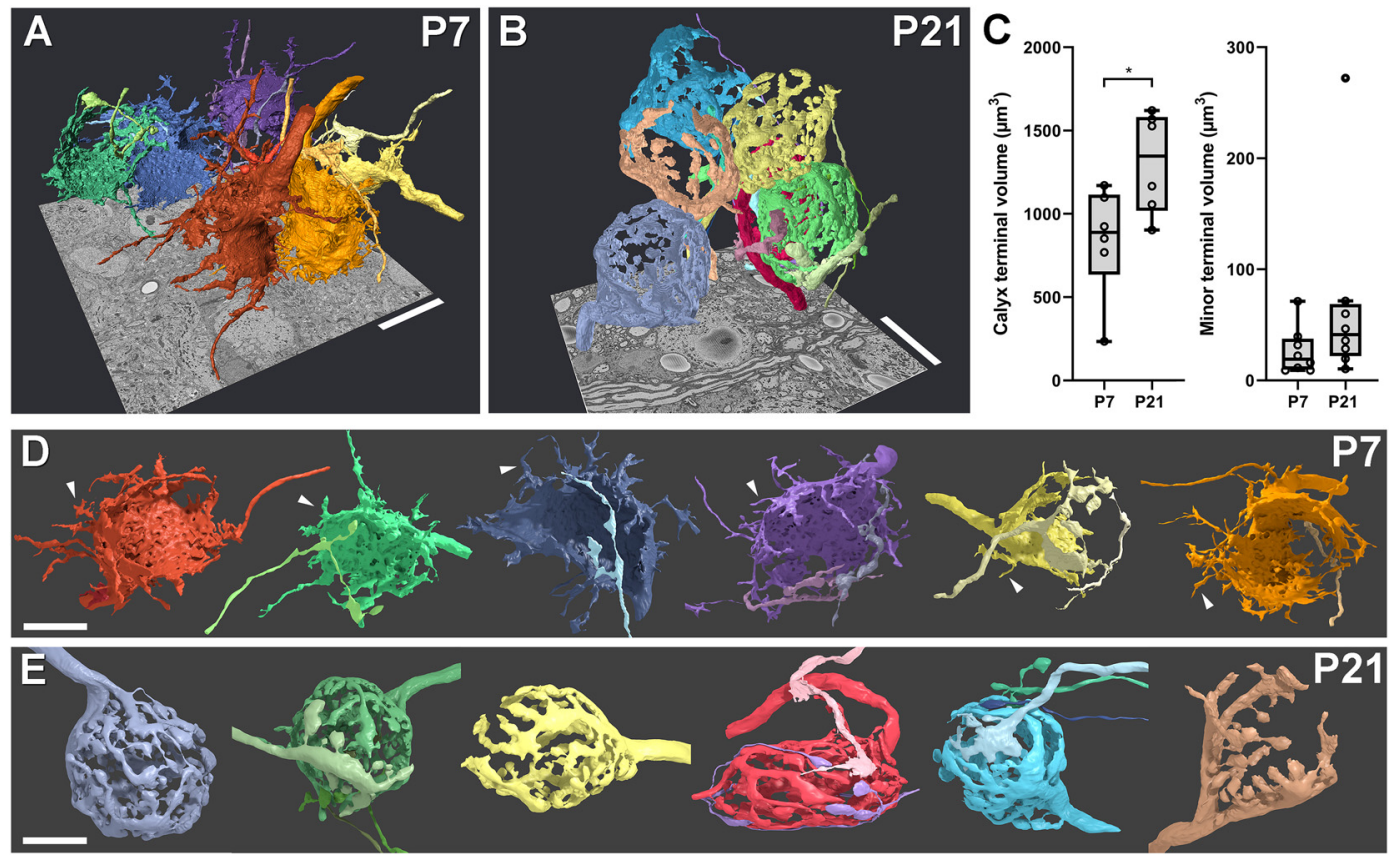

Figure 5. Large volume reconstructions of mito-APEX2-positive calyx of Held terminals using SBF-SEM at P7 $(\boldsymbol{A}, \boldsymbol{D})$ and P21 $(\boldsymbol{B}, \boldsymbol{E})$. $\boldsymbol{A}$, Volumetric positions of six transduced calyx terminals and eight minor inputs contacting six different MNTB principal cells (data not shown), reconstructed from a downsampled volume of $78 \times 78 \times 52 \mu \mathrm{m}$ at P7. $\boldsymbol{B}$, Volumetric positions of six transduced terminals with eight minor inputs contacting six principal cells (data not shown) reconstructed from a downsampled volume of $78 \times 78 \times 79 \mu \mathrm{m}$ at P21. $C$, Volumes of calyx terminal (left) and minor terminal (right) at P7 and P21. D, Individual renderings of mito-APEX2-positive calyx terminals together with one to three minor labeled terminals contacting each principal cell (data not shown). Several filopodia extend from the cup-like calyx terminals (examples, white arrowheads). $\boldsymbol{E}$, Individual renderings of mito-APEX2-positive calyx terminal inputs contacting principal cells (data not shown). Thick digitated terminals at P21 had few filopodial extensions, but three of six principal cells had minor labeled inputs (migratory calycigenic axons; second, fourth, and fifth from left). Box plot whiskers extend to the minimum/maximum within 1.5 interquartile range; open circles indicate individual terminals. Scale bars: $\boldsymbol{A}, \boldsymbol{B}, 20 \mu \mathrm{m} ; \boldsymbol{D}, \boldsymbol{E}, 10 \mu \mathrm{m} ;{ }^{*} p<0.05$.

of the terminal; a $\sim 2.6$-fold increase throughout development $(p<0.0001$; Fig. 6E; Table 2). Mitochondrial volumes in the minor terminals at both P7 and P21 showed a similar linear scaling of mitochondrial volumes (slope $=0.1883, R^{2}=0.99$ vs $\left.0.1066, R^{2}=0.95\right)$ and revealed a $\sim 40 \%$ increase in the mitochondrial volumes at P21 ( $p=0.0245$; Fig. $6 F)$.

During maturation, the calyx transforms into a high-fidelity synapse that can sustain AP firing upward to a kilohertz (Baydyuk et al., 2016). Because AP firing is an energetically expensive process (Harris et al., 2012), this suggested that mitochondria levels are increased in the axon also. To determine whether mitochondria volumes are increased in the axon to support the increased firing rates during development, we analyzed the mitochondrial volumes in the calyx axon. We found that at P7 mitochondria composed $6.4 \%$ of the axon volume, whereas at P21 the mitochondria volume was increased twofold, comprising $12.5 \%$ of 


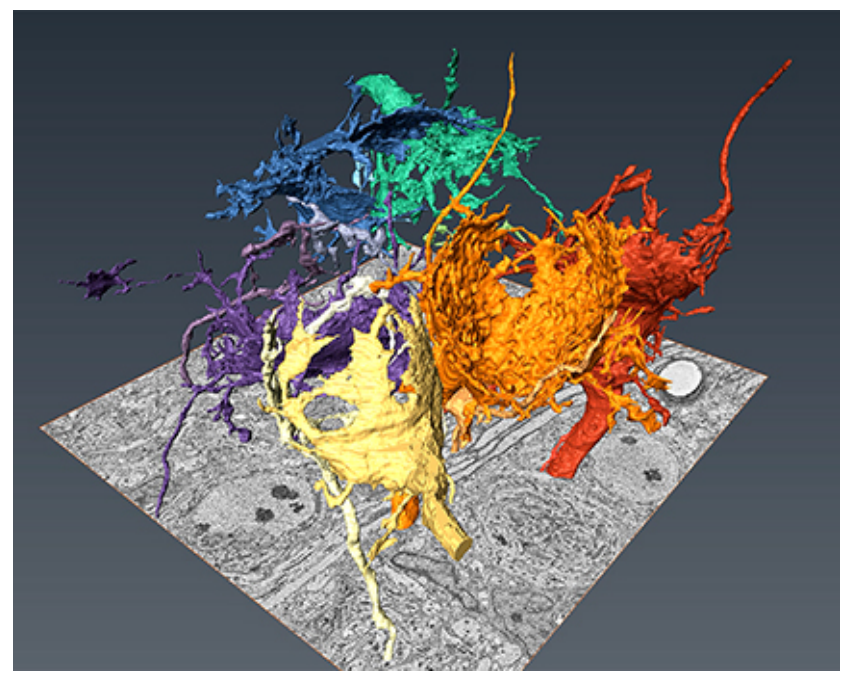

Movie 1. Whole reconstructions of calyx of Held terminals contacting six MNTB principal cells at P7 in a 78 by 78 by $52 \mu \mathrm{m}$ volume using SBF-SEM. Related to Figure $5 A$.

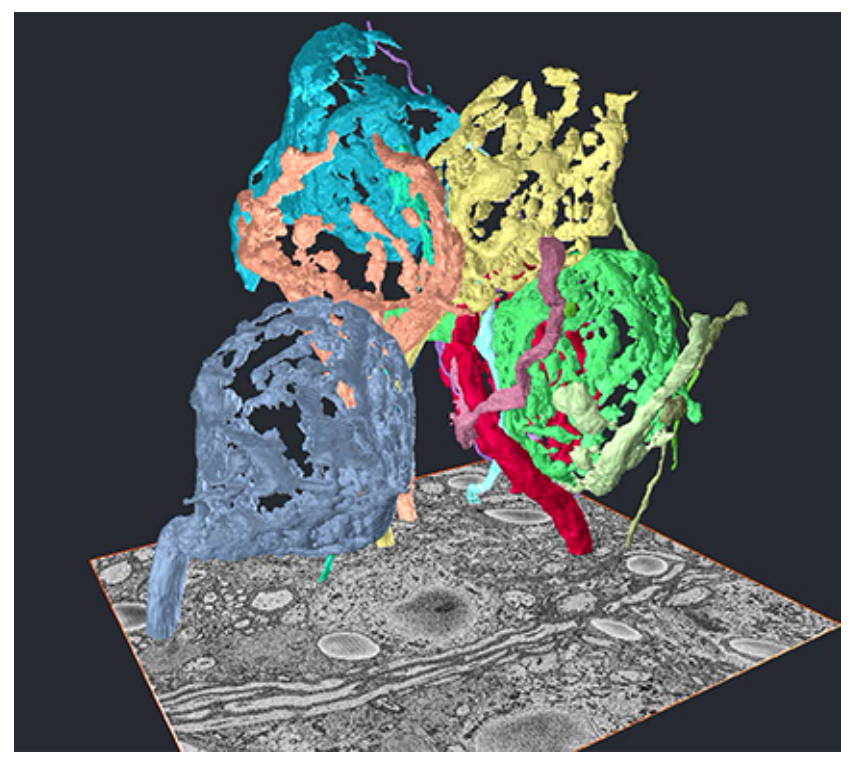

Movie 2. Whole reconstructions of calyx of Held terminals contacting six MNTB principal cells at $P 21$ in a 78 by 78 by $79 \mu \mathrm{m}$ volume using SBF-SEM. Related to Figure 5B.

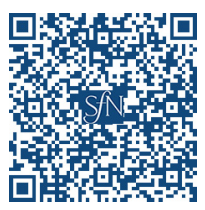

axon volume ( $p=0.0003)$. When comparing the relative mitochondrial volumes in the calyx terminal versus axon, we found that the calyx had significantly higher relative mitochondria volumes than the axon at P21 $(p=0.0009)$, whereas there was no difference between the P7 terminal and axon $(p=0.7116$; Fig. $6 E$; Table 2).

Together, our results revealed that mitochondrial volumes increase in both the calyx and its axon during maturation. Furthermore, mitochondrial volumes in the mature calyx are selectively increased compared with its respective axon, resulting in an asymmetry not found in the immature calyx. There- fore, we conclude that increases in mitochondrial volumes support the energetic demands required for high-fidelity synaptic transmission.

\section{Stalks and swellings of the mature calyx have similar relative} mitochondrial volumes

In the mature calyx, $\mathrm{Ca}^{2+}$ transients are higher in swellings compared with stalks, and stalks have higher Pr than swellings (Fekete et al., 2019). Because mitochondria can act as $\mathrm{Ca}^{2+}$ buffers, this suggests mitochondria volumes may be lower in swellings compared with stalks. In addition, swellings have more loosely coupled SVs than stalks, which are proposed to be in a less energetically favorable configuration (Eggermann et al., 2012). Therefore potential differences in coupling may impact mitochondrial volumes between the two subcompartments. To determine mitochondrial volumes in these subcompartments we segmented small subvolumes at full resolution and reconstructed mitochondria in 4 stalks and 22 swellings from two calyces (P21; Figs. 5E, 7C-E, far left and far right calyces). Subsequent analysis revealed that stalks and swellings contain similar relative volumes of mitochondria (stalks $=17.5 \%$ vs swellings $=21.4 \%$; Fig. $7 \mathrm{D}, \mathrm{E}$; Table 2).

Because we found that mitochondrial volumes in P21 calyces differ between axons and terminals (Fig. 6E), we further analyzed mitochondrial morphology by measuring the mitochondria diameter in axons (P7, P21), cup (P7), stalks, and swellings (P21) from the same full-resolution reconstruction of subcompartment data (Table 2). At P7, we found no difference between the mitochondrial diameters between axon and cup $(0.4 \pm 5 \mathrm{~nm}$ larger in the axon, $p>0.9999$; Fig. $7 F)$. Within subcompartments at P21 we found that stalks and swellings contained larger mitochondria diameters compared with the axon (44 $\pm 2 \mathrm{~nm}$ larger in stalks, $p<0.0001 ; 40 \pm 2 \mathrm{~nm}$ larger in swellings, $p$ $<0.0001)$, but found no difference between stalk and swellings ( $4 \pm 2 \mathrm{~nm}$ larger in stalks, $p=0.1173$ ). Across developmental stages, we observed an increase in the mitochondria diameter between P7 and P21 axons (21 \pm 4 nm larger at P21, $p<0.0001$; Fig. $7 F)$. Together, our findings reveal that stalks and swellings have similar mitochondrial volumes and diameters, and mitochondrial diameters are larger in P21 than in P7 calyces. Therefore, we conclude that differences in $\mathrm{Ca}^{2+}$ buffering between stalks and swellings are not caused by differences in mitochondrial volumes. Furthermore, the developmental increase in mitochondrial volumes is largely due to an increase in mitochondria size.

At P7, calyces had multiple filopodial extensions with various morphologies as shown in Figure 5, $A$ and $D$, some of which sparsely contained mitochondria (Fig. $6 A, C$ ). To further analyze the mitochondria distribution in these extensions we performed another full-resolution partial reconstruction of a P7 calyx and overlaid its segmented mitochondria (Fig. 8; Movie 5). In this terminal, extensions from the cup-like calyx rarely contained mitochondria (Fig. $8 B, D$ ). In addition, we found multiple invaginations into the calyx from the principal cell, including large excrescences with complex membrane topologies (Fig. 8A, C, white arrows). These excrescences were largely composed of principal cell processes, though some processes could be traced back to the calyx terminal (Movie 5). Similar to filopodial extensions, these structures lacked mitochondria. This indicates that at P7 mitochondria are mostly restricted to the cup. 
Table 2. Morphological data of the calyx of Held from SBF-SEM and ssSEM

\begin{tabular}{|c|c|c|c|c|c|c|c|c|c|}
\hline \multicolumn{10}{|c|}{ SBF-SEM whole-terminal reconstructions (Fig. 5) } \\
\hline Age & $\begin{array}{l}\text { Imaging } \\
\text { volume, } \mu \mathrm{m}\end{array}$ & $\begin{array}{l}\text { XYZ resolution, } \\
\mathrm{nm}\end{array}$ & $\begin{array}{l}\text { Imaging; } \\
\text { reconstruction hours }\end{array}$ & $\begin{array}{l}\text { Principal } \\
\text { cell ID }\end{array}$ & $\begin{array}{l}\text { Labeled terminals } \\
\text { perPC }\end{array}$ & $\begin{array}{l}\text { Main calyx terminal/minor } \\
\text { terminal volumes, } \mu \mathrm{m}^{3}\end{array}$ & $\begin{array}{l}\text { Statistical } \\
\text { test }\end{array}$ & $P$ & $\begin{array}{l}\text { Test } \\
\text { statistic }\end{array}$ \\
\hline \multirow[t]{7}{*}{ P7 } & $78 \times 78 \times 52$ & $6.5,6.5,70$ & $24 ; 40$ & 1 & 2 & $1170.67 / 9.10$ & Two-tailed $t$ test ${ }^{a}$ & 0.03 & $t_{(10)}=2.53$ \\
\hline & & & & 2 & 2 & $768.28 / 16.02$ & & & \\
\hline & & & & 3 & 2 & $923.64 / 11.48$ & & & \\
\hline & & & & 4 & 3 & $852.18 / 31.94,22.31$ & & & \\
\hline & & & & 5 & 3 & $234.08 / 71.30,9.12$ & & & \\
\hline & & & & 6 & 2 & $1098.44 / 39.52$ & & & \\
\hline & & & & & total $=14$ & mean $=841.21 / 26.35$ & & & \\
\hline \multirow[t]{7}{*}{ P21 } & $78 \times 78 \times 79$ & $6.5,6.5,70$ & $36 ; 100$ & 1 & 1 & 1620.24 & & & \\
\hline & & & & 2 & 4 & $1056.4 / 272.39,19.65,35.88$ & & & \\
\hline & & & & 3 & 1 & 902.78 & & & \\
\hline & & & & 4 & 3 & $1568.87 / 28.57,60.05$ & & & \\
\hline & & & & 5 & 4 & $1527.35 / 71.65,46.57,10.34$ & & & \\
\hline & & & & 6 & 1 & 1166.29 & & & \\
\hline & & & & & total $=14$ & mean $=1306.99 / 68.14$ & & & \\
\hline
\end{tabular}

SBF-SEM whole-terminal mitochondria reconstructions (Fig. 6)

\begin{tabular}{|c|c|c|c|c|c|c|c|c|c|c|c|c|}
\hline Age & $\begin{array}{l}\text { Reconstruction } \\
\text { hours }\end{array}$ & $\begin{array}{l}\text { Principal } \\
\text { cell } \\
\text { ID }\end{array}$ & $\begin{array}{l}\text { Main calyx } \\
\text { terminal mito } \\
\text { volume, } \mu \mathrm{m}^{3}\end{array}$ & $\begin{array}{l}\text { Calyx mito. } \\
\text { volume } \\
\text { fraction }\end{array}$ & $\begin{array}{l}\text { Axon volume } \\
\text { analyzed, } \\
\mu \mathrm{m}^{3}\end{array}$ & $\begin{array}{l}\text { Axon mito } \\
\text { volume, } \mu \mathrm{m}^{3}\end{array}$ & $\begin{array}{l}\text { Axon mito } \\
\text { volume } \\
\text { fraction }\end{array}$ & $\begin{array}{l}\text { Statistical } \\
\text { test }\end{array}$ & $P$ & $\begin{array}{l}\text { Test } \\
\text { statistic }\end{array}$ & $\begin{array}{l}\text { Multiple } \\
\text { comparisons } \\
P\end{array}$ & $\begin{array}{l}\text { Multiple- } \\
\text { comparison } \\
\text { test statistic }\end{array}$ \\
\hline \multirow[t]{4}{*}{ P7 } & 18 & 1 & 70.32 & 0.060 & 63.61 & 2.96 & 0.047 & Two-way RM ANOVA & Compartment $\times$ age: 0.0146 & $F_{(1,10)}=8.68$ & P7 axon vs P21 axon: 0.00027 & $t_{(20)}=4.71$ \\
\hline & & 2 & 70.45 & 0.092 & 62.84 & 5.62 & 0.089 & & Compartment: 0.0015 & $F_{(1,10)}=18.63$ & P7 terminal vs $P 21$ terminal: $<0.00001$ & $t_{(20)}=9.35$ \\
\hline & & 3 & 63.73 & 0.069 & 16.24 & 1.19 & 0.074 & & Age: $<0.00001$ & $F_{(1,10)}=129.70$ & P7 axon vs P7 terminal: 0.71162 & $t_{(10)}=0.96$ \\
\hline & & 4 & 64.92 & 0.076 & 101.31 & 7.25 & 0.072 & & & & P21 axon vs $P 21$ terminal: 0.00088 & $t_{(10)}=5.14$ \\
\hline
\end{tabular}

$\begin{array}{lll}\text { P21 } 48 \quad 1 & 340.68 \\ & 2 & 182.10 \\ & 3 & 186.43 \\ & 4 & 331.49 \\ & 5 & 296.80 \\ & 6 & 239.93\end{array}$

$\begin{array}{llll}0.089 & 47.99 & 2.55 & 0.053\end{array}$

$\begin{array}{llll}0.082 & 123.16 & 6.03 & 0.049\end{array}$

SBF-SEM subcompartment mitochondria analysis (Fig. 7)

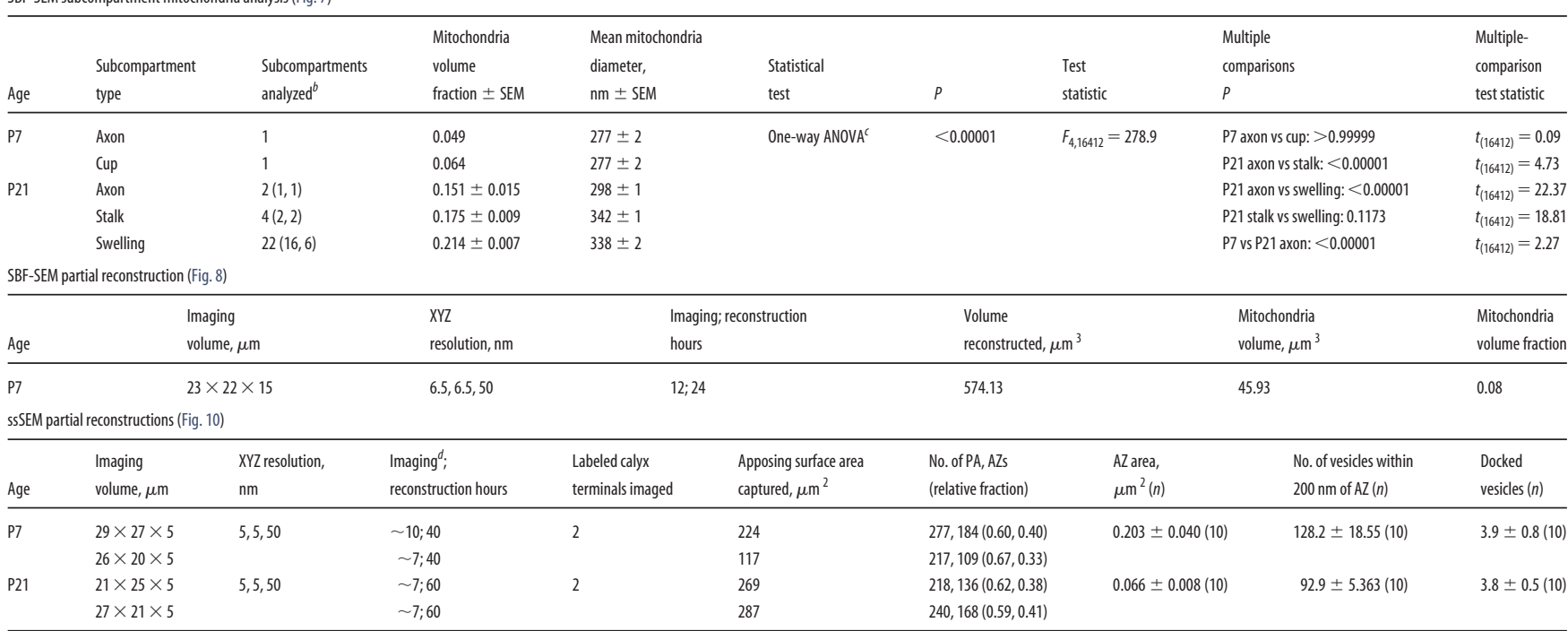

${ }^{a}$ Statistical analysis shown is for main calyx input volumes between P7 and P21.

${ }^{b}$ Two calyces were analyzed for P21 subcompartment analysis. Brackets show the number of subcompartments analyzed for the first and second calyx.

'Statistical analysis shown is for mitochondria diameter comparisons. Bonferroni's method was used for adjustment of $p$ values for multiple comparisons of means.

${ }^{d}$ Imaging hours for ssSEM are approximate because ROIs occasionally needed to be recaptured. For ssSEM vesicle and AZ analysis, five AZs were reconstructed from two cells and pooled. Statistics shown are mean \pm SEM.

Mito-APEX2 in conjunction with ATUM ssSEM allows for fine scale $3 \mathrm{D}$ analysis of presynaptic ultrastructure

In addition to using SBF-SEM in combination with mito-APEX2 to analyze mitochondrial volumes, one of our goals was to use mito-APEX2 as a genetic tool to analyze presynaptic ultrastructure in a defined population of genetically labeled neurons. However, we were unable to reliably detect the AZ with SBF-SEM. Therefore, we used ATUM-ssSEM to obtain SEM images with higher signal-to-noise ratio. We first established protocols to reliably detect mito-APEX2-labeled mitochondria with ATUM ssSEM and then used mito-APEX2 to carry out partial reconstructions of multiple AZs in the calyx.

Using our protocols, we could clearly identify labeled mitochondria in calyx terminals with detailed synaptic structure after poststaining sections to improve signal-to-noise ratio (SNR) for better membrane visualization in both P7 (Fig. 

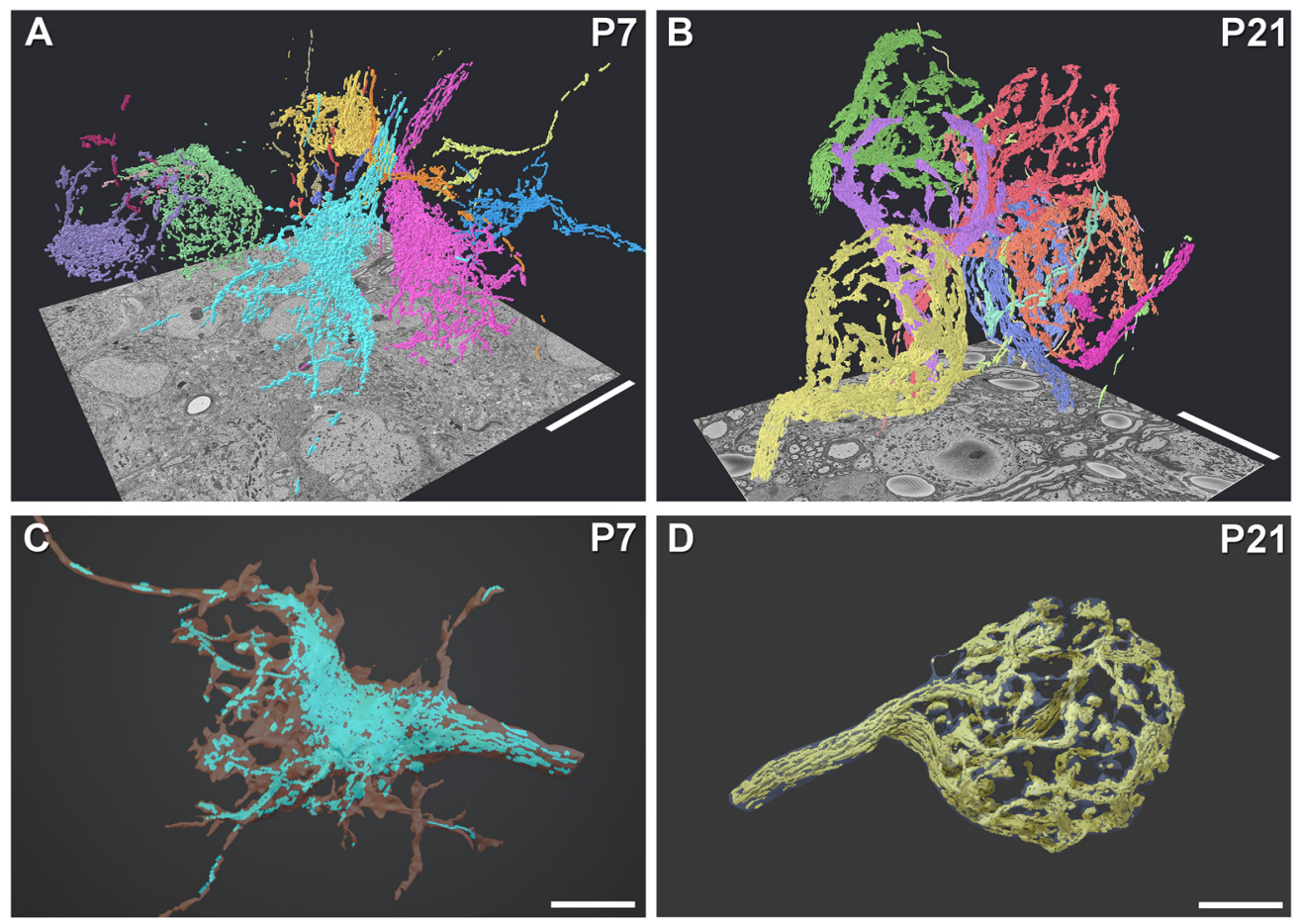

E

Calyx terminals
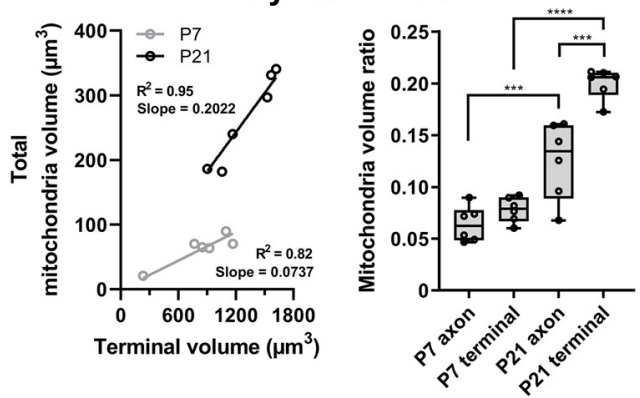

$\mathbf{F}$

Minor terminals
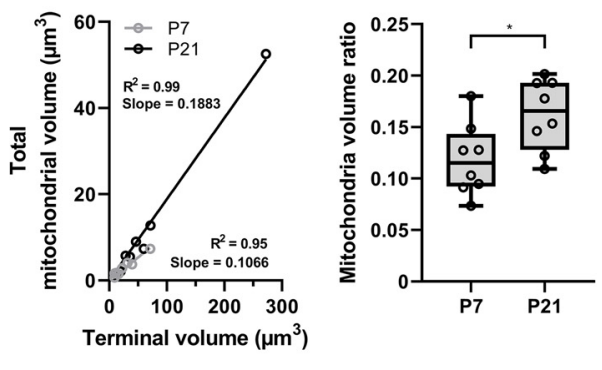

Figure 6. Volumetric reconstructions of mitochondria from the same whole terminals and axons shown in Figure 5 using SBF-SEM at P7 and P21. $A, B$, Volumetric positions of mito-APEX2-labeled mitochondria of the six calyx of Held terminals at P7 $(\boldsymbol{A})$ and P21 $(\boldsymbol{B}) . \boldsymbol{C}, \boldsymbol{D}$, individual renderings of mito-APEX2-labeled mitochondria with the membrane surface view of the whole terminals in transparent gray from one terminal at P7 (C) and P21 (D). $\boldsymbol{E}$, Mitochondrial volume scales linearly with the calyx terminal volume at both developmental stages. Mitochondrial volume ratio is not different between axons and terminals at $\mathrm{P7}$, but volume ratio does increase in axons and terminals across developmental stages. Ratios are also higher in P21 terminals compared with the P21 axons. $\boldsymbol{F}$, Mitochondrial volume scales linearly with terminal volume in minor terminals at both developmental stages. Mitochondria volume ratios are slightly higher in P21 minor terminals compared with P7. Box plot whiskers extend to the minimum/maximum within 1.5 interquartile range; open circles indicate individual axons or terminals. Scale bars: $\boldsymbol{A}, \boldsymbol{B}, 20 \mu \mathrm{m} ; \boldsymbol{C}, \boldsymbol{D} 10 \mu \mathrm{m} ;{ }^{*} p<0.05 ;{ }^{* * *} p<0.001 ;{ }^{* * *} p<0.0001$.

$9 A, B)$ and P21 (Fig. 9C,D; see Materials and Methods). Imaging with ssSEM was performed with several sessions at progressively higher resolutions. Beginning with a resolution of $2 \mu \mathrm{m} /$ pixel, we collected images covering each section on a wafer, which required approximately a few hours. Following this, we imaged a broad region of interest in the middle of the MNTB containing dozens of principal cells at $30 \mathrm{~nm} /$ pixel resolution and captured $\sim 500$ images to discriminate mitoAPEX2-labeled terminals and to identify potential sites containing the fewest section wrinkles. Finally, we captured high resolution images at $5 \mathrm{~nm} /$ pixel resolution and a pixel dwell time of $\sim 13 \mu \mathrm{s}$, which was sufficient for analysis of synaptic specializations (Fig. $9 B, D$, top). We morphologically differentiated AZs (Fig. 9B, $D$, top) from PA (Fig. 9B, $D$, bottom) and separately quantified them for each calyx. Similar to SBFSEM, we confirmed that calyx terminals containing mitoAPEX2-positive mitochondria could be differentiated in both P7 and P21 ATUM-ssSEM samples (Fig. 9E,F).
Next, using 100 high-resolution serial sections captured from both P7 and P21 samples expressing mito-APEX2, we created partial reconstructions and performed volumetric analysis for two calyces at each age (Fig. 10). The estimated surface areas of the partially reconstructed calyces facing the soma ranged from 117 to $269 \mu \mathrm{m}^{2}$. (Fig. 10 A, B; Table 2; Movies 6 and 7). At P7, the number of PAs was twofold higher than AZs ( $37 \% \mathrm{AZ}$ vs $63 \% \mathrm{PA}$; Fig. 10A; Table 2), similar to previously reported values in $\mathrm{P} 9$ rat (Sätzler et al., 2002). At P21 we observed a similar proportion of $40 \%$ AZ to $60 \%$ PA (Fig. 10B; Table 2).

Because both AZ size and SV distributions change during early development (Taschenberger et al., 2002), we analyzed AZ area and SV distributions of 10 individual AZs (5/calyx) from 3D reconstructed models at P7 and P21. We found larger AZ at P7 compared with P21 (P7: $0.203 \pm 0.040 \mu \mathrm{m}^{2}, n=10$ vs P21: $0.066 \pm 0.008 \mu \mathrm{m}^{2}, n=10$; Fig. 10C-E; Table 2). Comparing SV distribution within $200 \mathrm{~nm}$ of the $\mathrm{AZ}$ we found that $\mathrm{AZ}$ at $\mathrm{P} 7$ contained more SVs than P21 (P7: $128.2 \pm 18.55, n=10$; vs P21: 


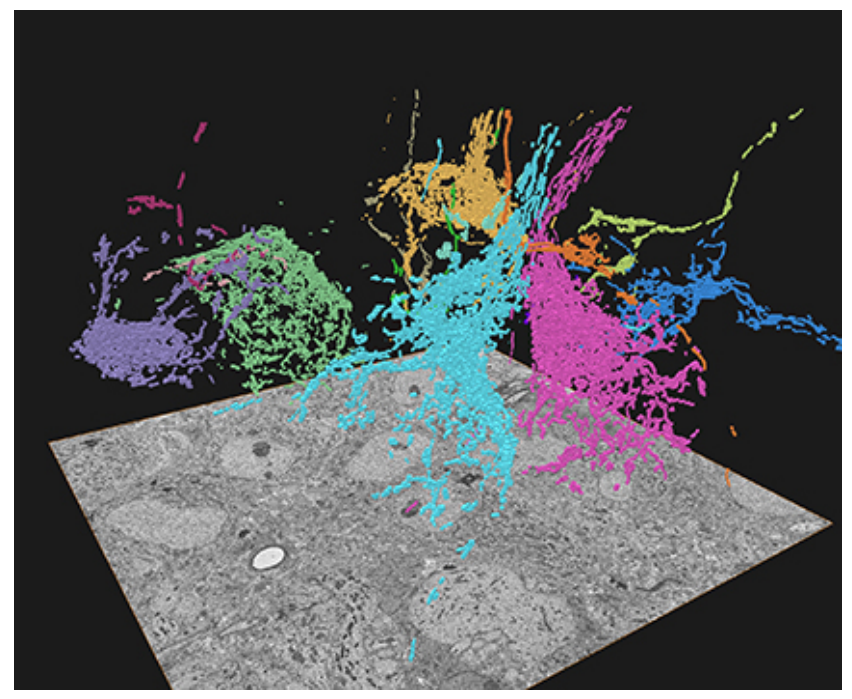

Movie 3. Mitochondria reconstructions of calyx of Held terminals contacting six MNTB principal cells at P7 in the same volume as Movie 3. Related to Figure $6 A$.

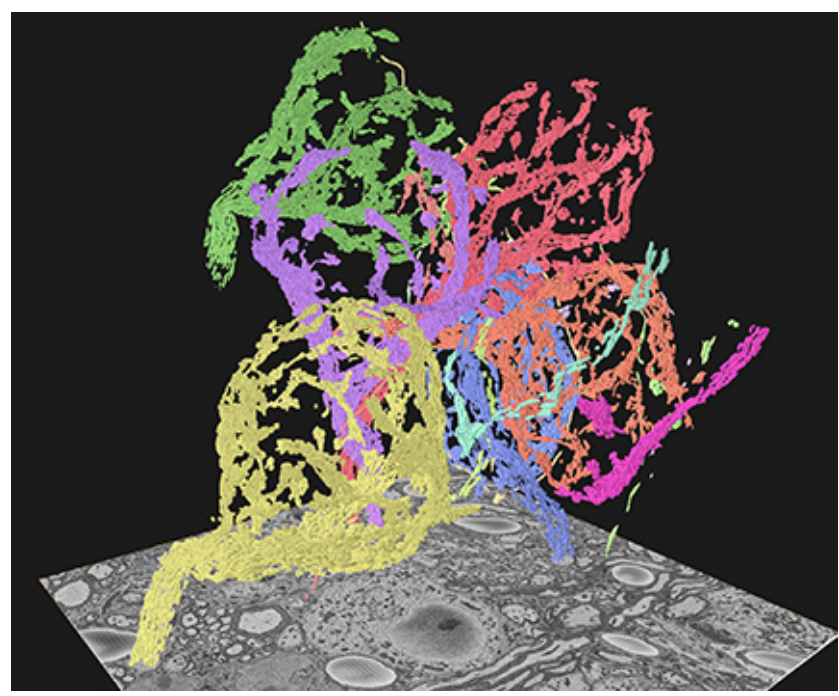

Movie 4. Mitochondria reconstructions of calyx of Held terminals contacting six MNTB principal cells at P21 in the same volume as Movie 4. Related to Figure $6 B$.

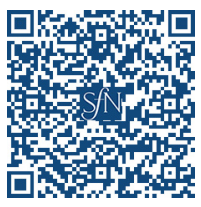

$92.9 \pm 5.36, n=10$; Fig. $10 F, G$; Table 2). However, when normalizing the SV number to AZ area to correct for the difference in AZ size, we found that the P21 AZ contained more SVs within 200 $\mathrm{nm}$ per AZ unit area (Fig. 10G). We observed no difference in overall SV distribution between P7 and P21 in a $200 \mathrm{~nm}$ distance from AZs in 3D space (Fig. 10H). At both ages, docked SVs $(<5 \mathrm{~nm}$ to $\mathrm{AZ}$ ) per AZ were similar (Table 2$)$ and comparable to previous reports (Sätzler et al., 2002; Taschenberger et al., 2002; Dondzillo et al., 2010), however, we did not observe a developmental decrease in contrast to a previous study (Taschenberger et al., 2002).

\section{Discussion}

To interrogate how mitochondria volumes are regulated during the development of the calyx of Held presynaptic terminal we developed a new tool, HdAd mito-APEX2, and optimized protocols and visualization workflows for use with SBF-SEM. We found that during development mitochondrial volumes increase in both the calyx and its respective axon, but that the mature calyx contains a larger relative mitochondrial volume than the axon. In addition, there was no difference in the relative mitochondrial volumes in the stalk and swellings of the mature calyx. Therefore, we propose that mitochondria levels are developmentally increased at the calyx of Held and its respective axon to support the energetic demands of high-frequency firing required to encode auditory information and may contribute to the calyx's morphological-functional diversity. Finally, we believe as a technical advancement, that our HdAd vector in combination with optimized protocols for ATUM-SEM and SBF-SEM will be of broad use in combination with molecular perturbations studies using LM and EM inside and outside of the neuroscience community.

A tubular network of mitochondria throughout development Whole-terminal volumetric reconstructions of mitochondria at the two developmental stages revealed a complex tubular network in the P7 and P21 calyx. These findings of many long fingerlike mitochondria are in line with previous reports from partial calyx reconstructions from P8 and P22 rats (Wimmer et al., 2006) and adult cat (Rowland et al., 2000) using ultrathin section TEM. Long tubular mitochondria have been observed in multiple neuron types and their respective axons and across species using different imaging modalities, EM, or fluorescence microscopy in both live cell and fixed tissues (Brodin et al., 1999; Misgeld et al., 2007; Saxton and Hollenbeck, 2012; Rossi and Pekkurnaz, 2019). However, the extensive tubular network might be specific to large synapses with high energy demands because many conventional presynaptic terminals in the CNS have a mitochondrion at or near the presynaptic terminal (Devine and Kittler, 2018). Because mitochondria can be functionally coupled (Amchenkova et al., 1988; Saxton and Hollenbeck, 2012), the tight packing and interconnected mitochondria observed in this and previous studies (Wimmer et al., 2006) suggest that mitochondria in the calyx and many other large presynaptic terminals are functionally coupled.

\section{Mitochondria become larger during calyx development}

Based on our finding that mitochondria are more densely packed and mitochondria volumes are higher in the mature calyx compared with immature calyx, we propose that a developmental increase in mitochondrial volumes is critical for high-frequency transmission. Qualitative analysis of P7 calyces revealed large patches of the calyx without mitochondria, whereas this was not found at the P21 calyx. Quantitative analysis of mitochondria diameters revealed that mitochondrial diameters were larger at the P21 calyces than those at P7. Though we found larger mitochondria at the mature stage, an increase in the total number of mitochondria may also contribute to the increase in relative volume. Obtaining absolute counts of mitochondria is difficult because of their ability to fuse and divide. However, qualitatively it appears that P21 calyces also contain more mitochondria. Although spontaneous activity in the auditory brainstem increases during early development (Tritsch and Bergles, 2010), the increase in mitochondrial volumes was larger at the calyx $(\sim 3-$ 
A P7 axon

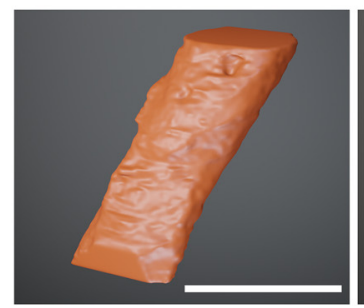

C P21 axon

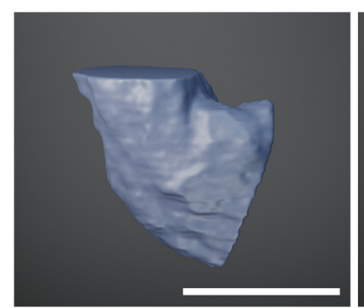

\section{E P21 swellings}

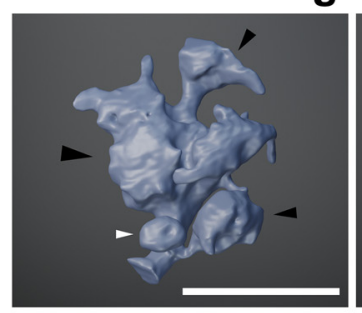

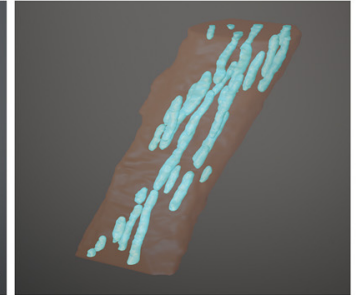
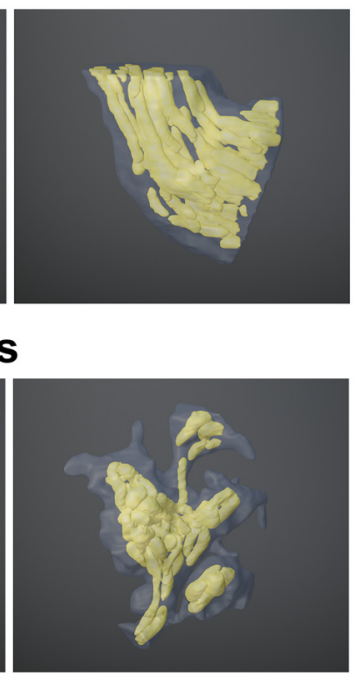

\section{B P7 cup}

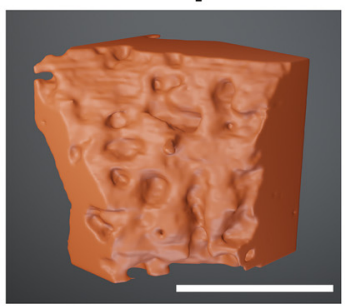

D P21 stalk
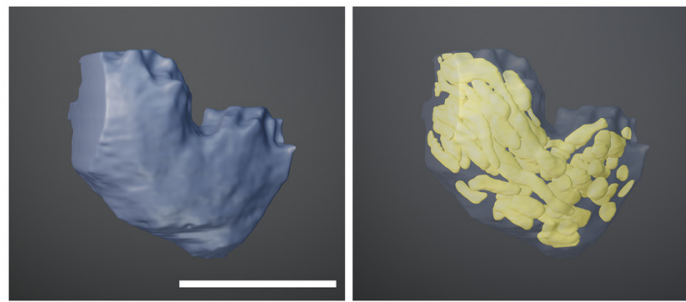

$\mathbf{F}$

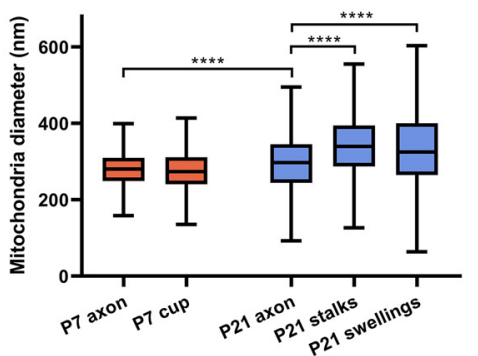

Figure 7. Full-resolution reconstructions of subcompartments and mitochondria of calyx of Held terminals at P7 and P21 using SBF-SEM. A-E, Reconstruction of a portion of P7 calyx of Held axon $(\boldsymbol{A})$ and terminal (cup; $\boldsymbol{B})$; and example reconstructions of a portion of P21 axon $(\boldsymbol{C})$, stalk $(\boldsymbol{D})$, and swellings $(\boldsymbol{E})$. Left images show the membrane surface views of the subcompartments and right images show the mitochondria inside. Black arrowheads $(\boldsymbol{E})$ point to several individual swellings of different sizes. White arrowhead indicates a small swelling not containing mitochondria. $\boldsymbol{F}$, Mitochondrial diameter comparison among subcompartments at P7 and P21. Box plot whiskers extend to the minimum/maximum within 1.5 interquartile range. Scale bars: $\boldsymbol{A}-\boldsymbol{E}, 5 \mu \mathrm{m} ;{ }^{* * *} p<0.0001$.
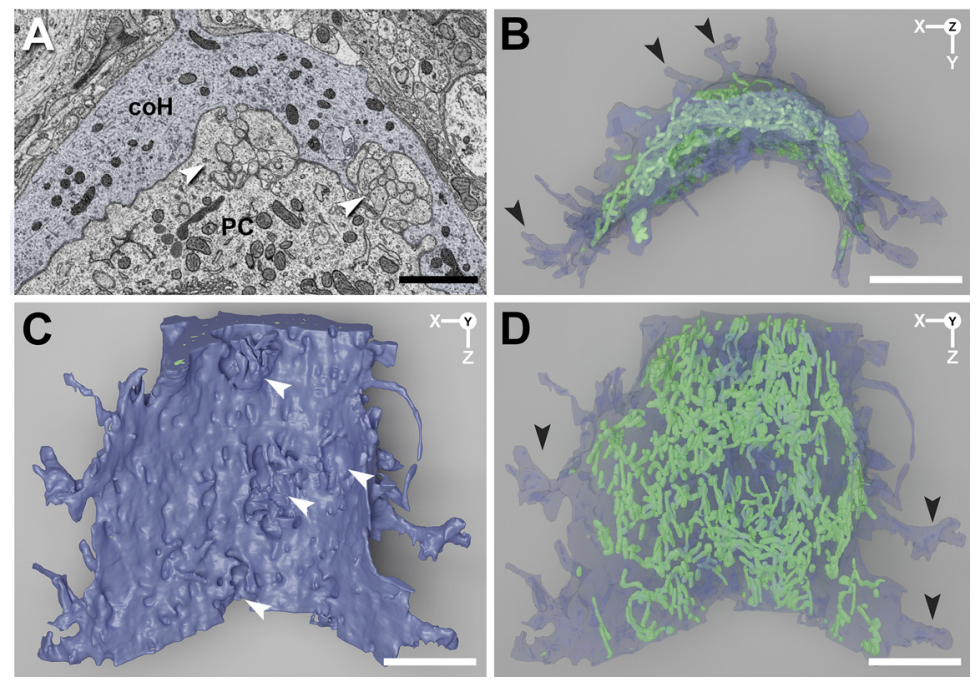

Figure 8. Mitochondria and membrane surface details of a segment of mito-APEX2-positive calyx of Held terminal reconstructed at full resolution from an SBF-SEM dataset at P7. A, Part of a block face image of the terminal (blue) showing the organization of electron dense mitochondria. The principal cell-contacting face of the calyx terminal revealed a complex membrane topology. Protrusions of the principal cell invade the calyx, visualized as indentations in the calyx membrane. White arrows highlight excrescences of the principal cell (also shown in $\boldsymbol{C}$. $\boldsymbol{B}$, Top-down view of the reconstructed terminal (blue) with mitochondria (green). Mitochondria are generally excluded from filopodial extensions of the calyx ( $\boldsymbol{B}, \boldsymbol{D}$, black arrows). $\boldsymbol{C}, \boldsymbol{D}$, Face-on view of terminal surface $(\boldsymbol{C})$ and mitochondria (green) within the terminal $(\boldsymbol{D})$, which form a complex network. Scale bars: $A-D, 5 \mu \mathrm{m}$. fold), compared with the secondary inputs $(\sim 1.4$-fold $)$ on the MNTB principal neuron. However, at P7 minor terminals had higher relative mitochondrial volumes $(\sim 2.5$-fold $)$ compared with the calyx.

What are the signals that promote this transformation? During calyx development, synaptic activity increases $\sim 10$ fold, which lead to high rates of SV release and replenishment (Baydyuk et al., 2016). Thus, a probable signal is synaptic activity, which is closely linked to mitochondria function (Nguyen et al., 1997; Rossi and Pekkurnaz, 2019). Total mitochondrial volume correlates with levels of exocytosis (Ivannikov et al., 2013), whereas individual mitochondrial volumes are larger at high-activity synapses (Cserép et al., 2018). In addition, mitochondria are more likely to pause during high activity levels and reside in the same position over a time course of days (Obashi and Okabe, 2013). Therefore, it is possible that the increase in calyx activity increases the residency time of mitochondria in the terminal. 


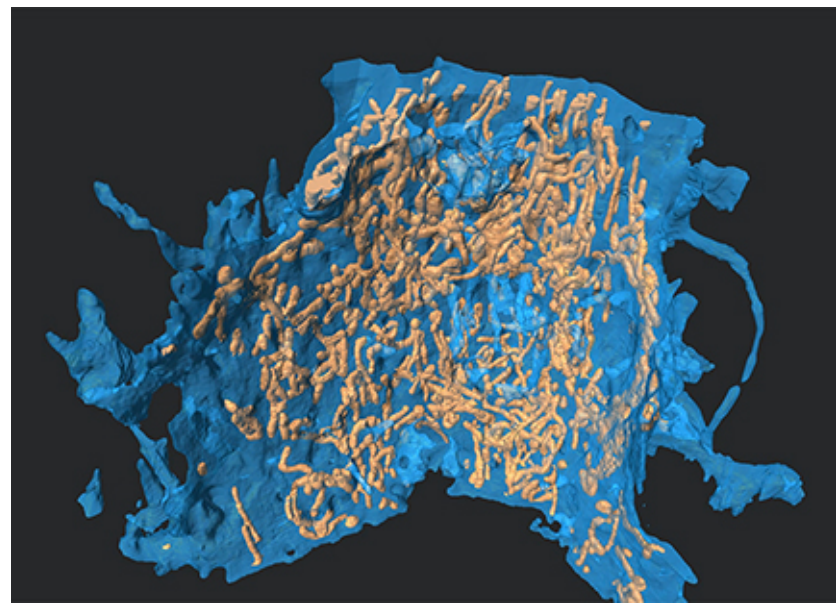

Movie 5. Semiautomated partial reconstruction of a calyx of Held terminal at P7 in a 23 by 22 by $15 \mu \mathrm{m}$ volume using SBF-SEM. Mitochondria (orange) were also semiautomatically segmented from the volume. Related to Figure 8.

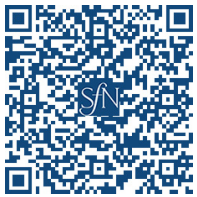

Comparison of axonal mitochondria volumes revealed that mitochondria were also more densely packed in P21 compared with P7. This indicates that increases in axonal excitability during development (Leão et al., 2005) are supported by increased mitochondria number to meet the energy demands of AP firing (Harris et al., 2012). Unlike the P7 axon, the mature calyx axon is myelinated except for the nodes of Ranvier and the heminode. $\mathrm{Na}^{+}$channels are highly clustered at the heminode and excluded from the terminal (Leão et al., 2005). Although the last heminode in the mature calyx axon is well defined using confocal imaging (Berret et al., 2016; Xu et al., 2017), we had difficulty defining the heminode from the myelination morphology only. Despite this, we were unable to detect any local increases in mitochondrial densities along the last $5-50 \mu \mathrm{m}$ of the axons in the recon- structed volume. Therefore, our data indicate that mitochondria levels in the axon are globally increased without higher densities at the heminode. However, because mitochondrial movement is on the order of seconds (Devine and Kittler, 2018 ) it is possible that mitochondria pause movement at these heminodes during AP firing to create temporary increases in density, which may not be detectable because of the timescale of aldehyde fixation.

We also found that mitochondrial volumes in the mature calyx were greater than its respective axon, whereas this was not found in the P7 calyx. This finding suggests that SV release and replenishment in the mature calyx has higher energetic demands than AP firing, whereas the energetic demands at P7 may be equivalent between the calyx and its respective axon. The mitochondrial adherens complex (MAC) is located within the mature calyx but has not been reported in the axon (Rowland et al., 2000). Therefore, it is possible that the MAC contributes to the increase in mitochondrial volume at the mature calyx because of its tethering of mitochondria. However, because of the limitations of SBF-SEM we were unable to identify the MAC and determine whether the complex appearance of mitochondria in the calyx is developmentally regulated. Future studies will need to be carried out to investigate this further.

\section{Mitochondria and their contribution to the calyx morphological-functional continuum}

Although the calyx is considered a reliable relay synapse (Englitz et al., 2009; Lorteije et al., 2009; Stasiak et al., 2018) a morphological-functional continuum of calyces that differ in the number of stalks and swellings in the hearing animal has been observed (Grande and L. Y. Wang, 2011; T. Wang et al., 2015). These differences in calyx morphologies corresponded to different short-term plasticity phenotypes, with simple calyces being strongly depressing and highly fenestrated calyces initially facilitating with less depression in response to train stimuli (Grande and L. Y. Wang, 2011). Differences in $\mathrm{Ca}^{2+}$ buffering and $\mathrm{Pr}$
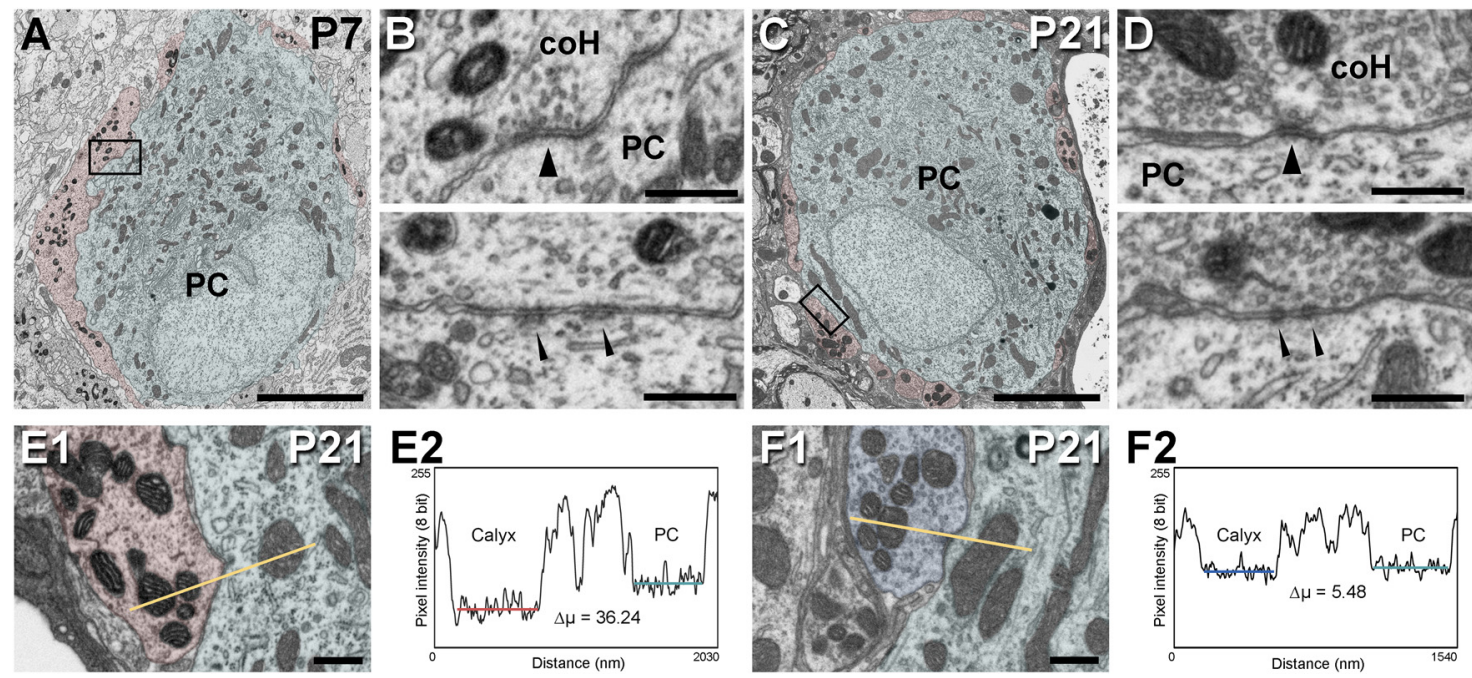

F2

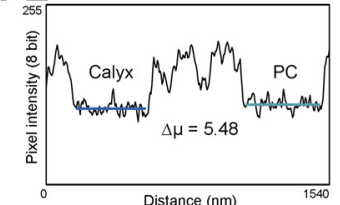

Figure 9. Mito-APEX2 labeling visualized by ssSEM at P7 $(\boldsymbol{A}, \boldsymbol{B})$ and $\mathrm{P} 21(\boldsymbol{C}, \boldsymbol{D}, \boldsymbol{E}$ 1) allows for identification of transduced calyx of Held terminals. $A, C$, Ultrathin sections show calyx of Held input $(\mathrm{COH} ;$; red) to an MNTB principal cell (PC; aqua) at P7 and P21, respectively. $\boldsymbol{B}, \mathbf{D}$, Zoomed view of the terminals (top) depicted in $\boldsymbol{A}$ or $\boldsymbol{C}$, respectively, showing electron-dense mitochondria and an AZ (top, thick arrowheads). PA (bottom, thin arrowheads) are also located at the CoH-PC interface. High SNR by ssSEM imaging allows for discrimination of individual SVs as well as presynaptic and postsynaptic densities. E1, Transduced terminals contain darker mitochondria compared with mitochondria of the opposing PC. F1, Nontransduced terminal mitochondria compared with the PC mitochondria. E2, F2, Intensity line profiles of mitochondrial intensity in transduced and nontransduced terminals; $\Delta \mu=$ difference in mean pixel intensity between calyx and $\mathrm{PC}$ mitochondria respectively. Scale bars: $\boldsymbol{A}, \boldsymbol{C}, 5 \mu \mathrm{m} ; \boldsymbol{B}, \boldsymbol{D}-\boldsymbol{F}, 500 \mathrm{~nm}$. 

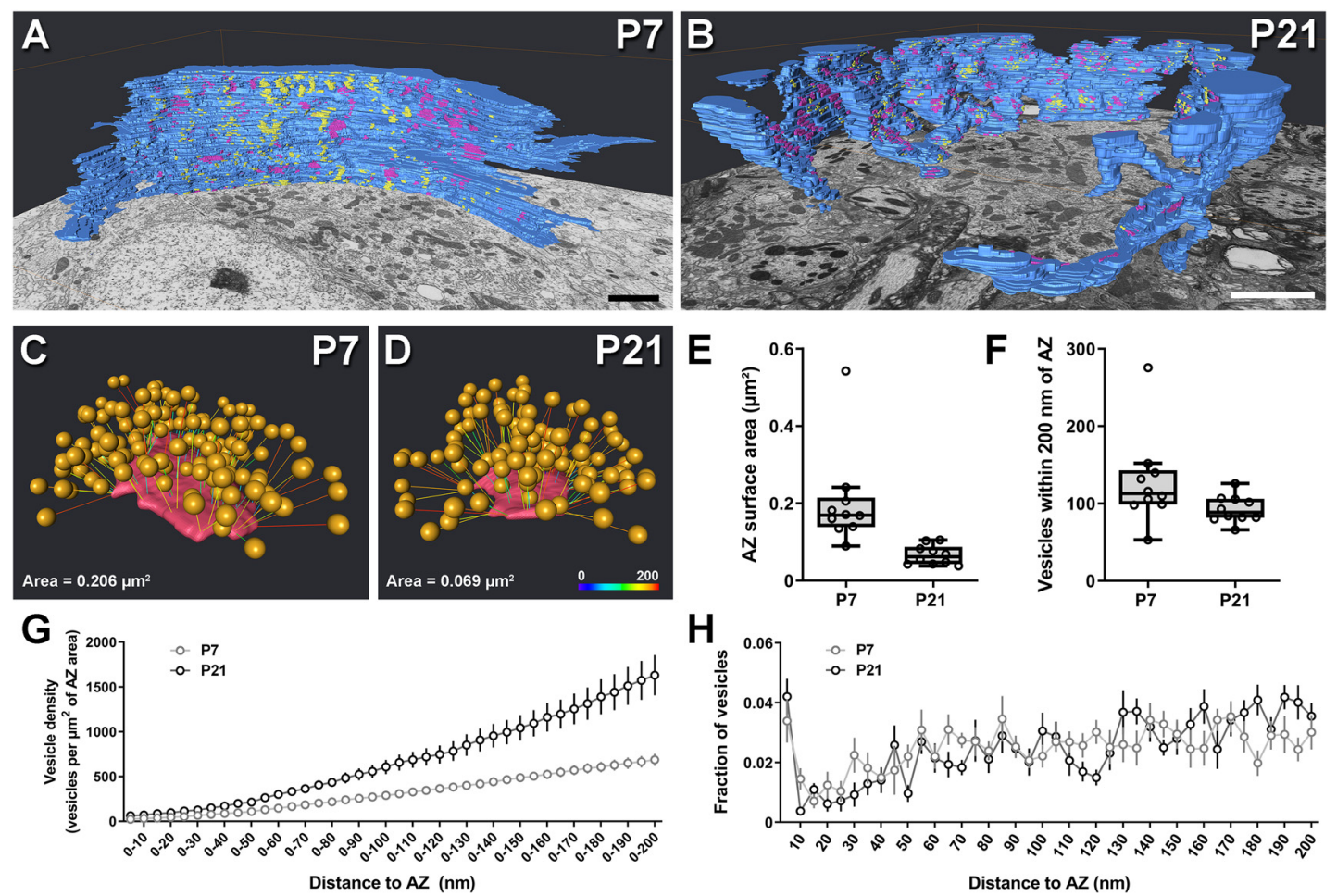

Figure 10. Identification of transduced terminals by ssSEM for 3D synaptic analysis. $A, B$, Partial $3 D$ reconstructions from 100 serial sections of the calyx of Held terminals at P7 (A) and P21 (B), respectively, showing AZs (pink) and PA (yellow). C, D, Ball models of an example AZ (pink) at the coH-MNTB synapse. SVs within $200 \mathrm{~nm}$ of the presynaptic membrane are modeled in 3D as $46 \mathrm{~nm}$ spheres (orange). Distances to the AZ from 0 to $200 \mathrm{~nm}$ are represented as colored lines. E, AZ surface area at P7 and P21. F, Total number of vesicles within $200 \mathrm{~nm}$ of the AZ. G, Vesicle density as a function of AZ area, binned from 0 to $200 \mathrm{~nm}$ from the $A Z$. $H$, Fraction of $S V$ s within $5 \mathrm{~nm}$ bins up to $200 \mathrm{~nm}$ from the AZ. Box plot whiskers extend to the minimum/maximum within 1.5 interquartile range; open circles indicate individual observations. Scale bars: $A, B, 5 \mu \mathrm{m} ; C$, colorimetric scale bar $0-200 \mathrm{~nm}$.

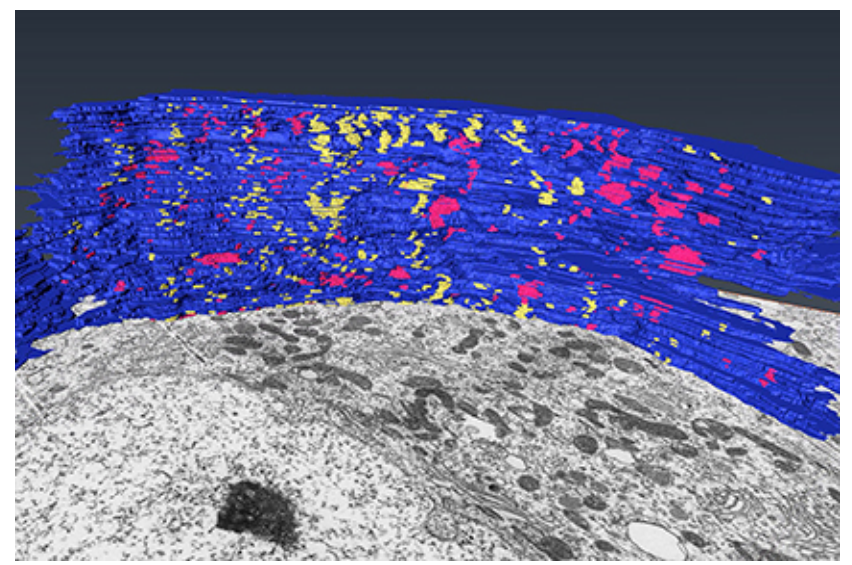

Movie 6. Partial reconstruction of a labeled calyx of Held terminal at P7 in a 26 by 20 by $5 \mu \mathrm{m}$ volume using ssSEM. AZs (pink) and PA (yellow) are shown on the calyx face in contact with the MNTB principal cell. Related to Figure $10 \mathrm{~A}$.

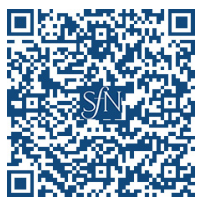

between stalks and swellings has been proposed to expand the coding capacity of the calyx/MNTB synapse (Fekete et al., 2019). Mitochondria contribute to $\mathrm{Ca}^{2+}$ buffering (Billups and Forsythe, 2002; Guo et al., 2005; Verstreken et al., 2005), which can impact SV release (Devine and Kittler, 2018). In particular at the prehearing calyx, mitochondria slow the clearance of $\mathrm{Ca}^{2+}$, which can impact sustained synaptic transmission (Billups and Forsythe, 2002). However, at the prehearing calyx, mitochondria contribution to synaptic transmission is only prominent when

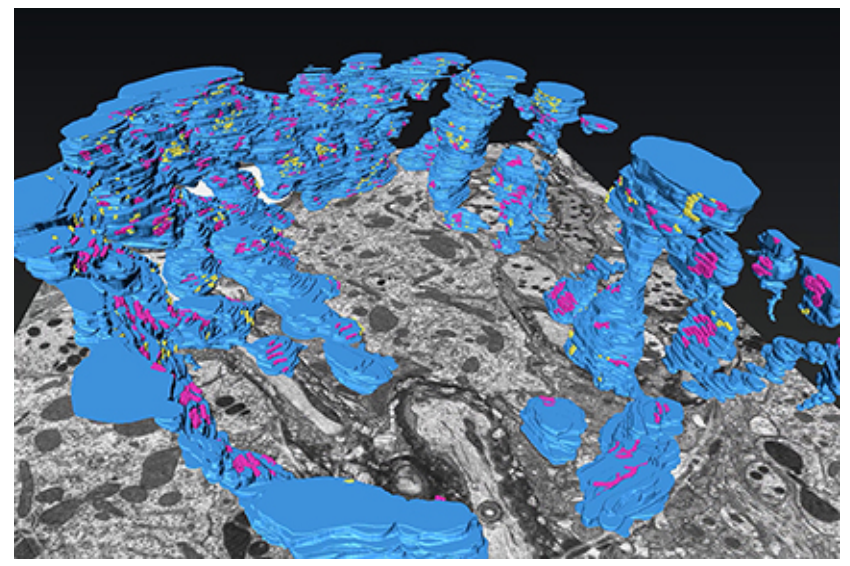

Movie 7. Partial reconstruction of a labeled calyx of Held terminal at P21 in a 27 by 21 by $5 \mu \mathrm{m}$ volume using ssSEM. AZs (pink) and PA (yellow) are shown on the calyx face in contact with the MNTB principal cell. Related to Figure $10 B$.

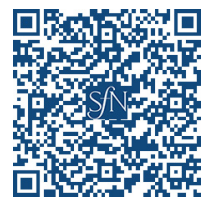

the $\mathrm{Na}^{+} / \mathrm{Ca}^{2+}$ exchanger is saturated (Kim et al., 2005). Although swellings contain larger and faster $\mathrm{Ca}^{2+}$ transients and more Cav2.1 channel clusters (Fekete et al., 2019), we found no difference in the relative mitochondria volumes between stalks and swellings. Thus, it is possible that the contribution of mitochondria to the morphological-functional continuum may be minimal. However, we did not perform functional analysis to perturb mitochondria and determine the impact on synapses in stalks and swelling. In addition, it is possible that only under long 
periods of high firing rates would mitochondria contribute to difference in $\mathrm{Ca}^{2+}$ clearance in these subcompartments. Future studies will need to be carried out to further investigate whether mitochondrial play a role in the morphological-functional continuum.

\section{Identification of multiple inputs at the principal cells of the MNTB}

Consistent with a previous report (Hoffpauir et al., 2006), we found multiple inputs innervating the MNTB principal neuron at P7. Strikingly, at P21 we also found labeled minor terminals in addition to a single calyx terminal. Although injection of HdAd with the human synapsin promoter labels other cell types in the $\mathrm{CN}$ in addition to the globular bushy cells (GBCs; Montesinos et al., 2011), none of these other cell types are reported to make synapses on MNTB principal cells (Cant and Benson, 2003). Therefore, these labeled terminals are likely of GBC origin and distinct from local excitatory and inhibitory inputs (Hamann et al., 2003; Albrecht et al., 2014). Because of limited volumes imaged in this study we were unable to traces these axons to their origin. Because GBC axons give rise to multiple collaterals that form other small terminals (coincident) onto MNTB cells (Morest, 1968; Rodríguez-Contreras et al., 2006, 2008) it is possible that they are the source of the minor terminals that we observed. Future studies will need to be carried out to determine their role in regulating $\mathrm{AP}$ firing in the $\mathrm{MNTB}$ principal neuron.

\section{HdAd mito-APEX2 as presynaptic marker for morphological studies}

HdAds are a dsDNA viruses and have faster onset of transgene expression than single-stranded rAAVs, which require secondstrand synthesis (Hastie and Samulski, 2015; Montesinos et al., 2016). We took advantage of this fast onset of expression and performed the EM analysis as early as P7, $6 \mathrm{~d}$ after HdAd injection, to analyze immature calyx ultrastructure. Although we did not test earlier time points, HdAd vectors have led to successful transduction of calyces as early as $72 \mathrm{~h}$ (Montesinos et al., 2011). Because HdAd expression allows for long-term expression of transgenes for years (Kim et al., 2001) and our data demonstrate lack of toxicity of synapsin promoter driven expression of EGFP and mito-APEX2, this suggests that use of HdAd EGFP-mito-APEX2 will enable long-term morphological studies on the scales of months to possibly years. More importantly, our HdAd vectors allows for the labeling of specific populations of neurons. When using mitochondria for volumetric reconstruction, the cellular compartments of interest should have a high mitochondria density for reliable distinction from unlabeled cells or compartments.

\section{ATUM ssSEM versus SBF-SEM for presynaptic ultrastructure analysis}

Use of HdAd mito-APEX2 with ATUM ssSEM allowed us to analyze presynaptic ultrastructure in addition to mitochondrial volumes. Both SBF-SEM and ATUM ssSEM have their strengths and weaknesses, therefore the different visualization platforms should be selected based on the target ultrastructure. Although SBF-SEM permitted large-scale volumetric analysis, we were unable to segment fine AZ structures, such as the MAC or the puncta adherentia because of the low SNR required for consistent sectioning. Additionally, the low SNR prevented analysis of SV distribution. The low SNR was a result of the minimum acceptable beam dosage required to avoid sample damage and achieve consistent cutting of the block. Future improvements will need to be developed to enable better SNR in combination with thinner cutting thickness for fine structure analysis. Because ATUM ssSEM allows longer dwell times and therefore better SNR than SBF-SEM it was ideal for measuring SV distributions and AZ areas in a relatively large terminal. However, the tradeoff is the inherent issue with section alignment and possible compression artifacts, thus ATUM ssSEM is ideal for small-scale volumetric reconstructions. Using ATUM ssSEM we found that the SV density per AZ area increases during development. Whereas a previous study found a decrease in docked SV number from P5 to P14 (Taschenberger et al., 2002), we observed no change between P7 and P21. However, we only analyzed $10 \mathrm{AZs}$ at each stage and differences in fixation protocols may lead to this discrepancy. Together, we believe that our viral vector and methods will be broadly applicable to quantitative analyses of subsynaptic organization of SVs, mitochondria, and their morphological continuum using TEM, ssSEM, and SBF-SEM.

\section{References}

Albrecht O, Dondzillo A, Mayer F, Thompson JA, Klug A (2014) Inhibitory projections from the ventral nucleus of the trapezoid body to the medial nucleus of the trapezoid body in the mouse. Front Neural Circuits 8:83.

Amchenkova AA, Bakeeva LE, Chentsov YS, Skulachev VP, Zorov DB (1988) Coupling membranes as energy-transmitting cables: I. Filamentous mitochondria in fibroblasts and mitochondrial clusters in cardiomyocytes. J Cell Biol 107:481-495.

Awatramani GB, Turecek R, Trussell LO (2004) Inhibitory control at a synaptic relay. J Neurosci 24:2643-2647.

Baydyuk M, Xu J, Wu LG (2016) The calyx of held in the auditory system: structure, function, and development. Hear Res 338:22-31.

Belevich I, Joensuu M, Kumar D, Vihinen H, Jokitalo E (2016) Microscopy image browser: A platform for segmentation and analysis of multidimensional datasets. PLoS Biol 14:e1002340.

Berret E, Kim SE, Lee SY, Kushmerick C, Kim JH (2016) Functional and structural properties of ion channels at the nerve terminal depends on compact myelin. J Physiol 594:5593-5609.

Billups B, Forsythe ID (2002) Presynaptic mitochondrial calcium sequestration influences transmission at mammalian central synapses. J Neurosci 22:5840-5847.

Borst JG, Soria van Hoeve J (2012) The calyx of held synapse: from model synapse to auditory relay. Annu Rev Physiol 74:199-224.

Brodin L, Bakeeva L, Shupliakov O (1999) Presynaptic mitochondria and the temporal pattern of neurotransmitter release. Philos Trans R Soc Lond B Biol Sci 354:365-372.

Cant NB, Benson CG (2003) Parallel auditory pathways: projection patterns of the different neuronal populations in the dorsal and ventral cochlear nuclei. Brain Res Bull 60:457-474.

Chen Z, Cooper B, Kalla S, Varoqueaux F, Young SM Jr (2013) The Munc13 proteins differentially regulate readily releasable pool dynamics and calcium-dependent recovery at a central synapse. J Neurosci 33:83368351.

Chen Z, Das B, Nakamura Y, DiGregorio DA, Young SM Jr (2015) $\mathrm{Ca}^{2+}$ channel to synaptic vesicle distance accounts for the readily releasable pool kinetics at a functionally mature auditory synapse. J Neurosci 35 : 2083-2100.

Cserép C, Pósfai B, Schwarcz AD, Dénes Á (2018) Mitochondrial ultrastructure is coupled to synaptic performance at axonal release sites. eNeuro 5:ENEURO.0390-17.2018.

Devine MJ, Kittler JT (2018) Mitochondria at the neuronal presynapse in health and disease. Nat Rev Neurosci 19:63-80.

Dondzillo A, Sätzler K, Horstmann H, Altrock WD, Gundelfinger ED, Kuner $\mathrm{T}$ (2010) Targeted three-dimensional immunohistochemistry reveals localization of presynaptic proteins bassoon and piccolo in the rat calyx of held before and after the onset of hearing. J Comp Neurol 518:1008-1029.

Dong W, Radulovic T, Goral RO, Thomas C, Suarez Montesinos M, Guerrero-Given D, Hagiwara A, Putzke T, Hida Y, Abe M, Sakimura K, Kamasawa N, Ohtsuka T, Young SM Jr (2018) CAST/ELKS proteins control voltage-gated $\mathrm{Ca}^{2+}$ channel density and synaptic release probability at a mammalian central synapse. Cell Rep 24:284-293.e6. 
Eggermann E, Bucurenciu I, Goswami SP, Jonas P (2012) Nanodomain coupling between $\mathrm{Ca}^{2+}$ channels and sensors of exocytosis at fast mammalian synapses. Nat Rev Neurosci 13:7-21.

Englitz B, Tolnai S, Typlt M, Jost J, Rübsamen R (2009) Reliability of synaptic transmission at the synapses of held in vivo under acoustic stimulation. PloS One 4:e7014.

Fedchyshyn MJ, Wang LY (2005) Developmental transformation of the release modality at the calyx of held synapse. J Neurosci 25:4131-4140.

Fekete A, Nakamura Y, Yang YM, Herlitze S, Mark MD, DiGregorio DA, Wang LY (2019) Underpinning heterogeneity in synaptic transmission by presynaptic ensembles of distinct morphological modules. Nat Commun 10:826.

Grande G, Wang LY (2011) Morphological and functional continuum underlying heterogeneity in the spiking fidelity at the calyx of held synapse in vitro. J Neurosci 31:13386-13399.

Guo X, Macleod GT, Wellington A, Hu F, Panchumarthi S, Schoenfield M, Marin L, Charlton MP, Atwood HL, Zinsmaier KE (2005) The GTPase dMiro is required for axonal transport of mitochondria to Drosophila synapses. Neuron 47:379-393.

Hamann M, Billups B, Forsythe ID (2003) Non-calyceal excitatory inputs mediate low fidelity synaptic transmission in rat auditory brainstem slices. Eur J Neurosci 18:2899-2902.

Harris JJ, Jolivet R, Attwell D (2012) Synaptic energy use and supply. Neuron 75:762-777.

Hastie E, Samulski RJ (2015) Adeno-associated virus at 50: a golden anniversary of discovery, research, and gene therapy success - a personal perspective. Hum Gene Ther 26:257-265.

Hentschke H, Stüttgen MC (2011) Computation of measures of effect size for neuroscience datasets. Eur J Neurosci 34:1887-1894.

Hoffpauir BK, Grimes JL, Mathers PH, Spirou GA (2006) Synaptogenesis of the calyx of held: rapid onset of function and one-to-one morphological innervation. J Neurosci 26:5511-5523.

Holcomb PS, Hoffpauir BK, Hoyson MC, Jackson DR, Deerinck TJ, Marrs GS, Dehoff M, Wu J, Ellisman MH, Spirou GA (2013) Synaptic inputs compete during rapid formation of the calyx of held: a new model system for neural development. J Neurosci 33:12954-12969.

Horstmann H, Körber C, Sätzler K, Aydin D, Kuner T (2012) Serial section scanning electron microscopy (S3EM) on silicon wafers for ultrastructural volume imaging of cells and tissues. PloS One 7:e35172.

Ivannikov MV, Sugimori M, Llinás RR (2013) Synaptic vesicle exocytosis in hippocampal synaptosomes correlates directly with total mitochondrial volume. J Mol Neurosci 49:223-230.

Iwasaki S, Takahashi T (2001) Developmental regulation of transmitter release at the calyx of held in rat auditory brainstem. J Physiol 534: $861-871$.

Kandler K, Friauf E (1993) Pre- and postnatal development of efferent connections of the cochlear nucleus in the rat. J Comp Neurol 328: 161-184.

Kim IH, Józkowicz A, Piedra PA, Oka K, Chan L (2001) Lifetime correction of genetic deficiency in mice with a single injection of helper-dependent adenoviral vector. Proc Natl Acad Sci U S A 98:13282-13287.

Kim MH, Korogod N, Schneggenburger R, Ho WK, Lee SH (2005) Interplay between $\mathrm{Na}+/ \mathrm{Ca}^{2+}$ exchangers and mitochondria in $\mathrm{Ca}^{2+}$ clearance at the calyx of held. J Neurosci 25:6057-6065.

Lam SS, Martell JD, Kamer KJ, Deerinck TJ, Ellisman MH, Mootha VK, Ting AY (2015) Directed evolution of APEX2 for electron microscopy and proximity labeling. Nat Methods 12:51-54.

Leão RM, Kushmerick C, Pinaud R, Renden R, Li GL, Taschenberger H, Spirou G, Levinson SR, von Gersdorff H (2005) Presynaptic Na+ channels: locus, development, and recovery from inactivation at a high-fidelity synapse. J Neurosci 25:3724-3738.

Lee A, Hirabayashi Y, Kwon SK, Lewis TL Jr, Polleux F (2018) Emerging roles of mitochondria in synaptic transmission and neurodegeneration. Curr Opin Physiol 3:82-93.

Lichtman JW, Denk W (2011) The big and the small: challenges of imaging the brain's circuits. Science 334:618-623.

Lidierth M (2009) sigTOOL: a MATLAB-based environment for sharing laboratory-developed software to analyze biological signals. J Neurosci Methods 178:188-196.

Lorteije JA, Rusu SI, Kushmerick C, Borst JG (2009) Reliability and precision of the mouse calyx of held synapse. J Neurosci 29:13770-13784.
Lowe DG (2004) Distinctive image features from scale-invariant keypoints. Int J Comput Vis 60:91-110.

Lübbert M, Goral RO, Satterfield R, Putzke T, van den Maagdenberg AM, Kamasawa N, Young SM Jr (2017) A novel region in the CaV2.1 alpha1 subunit C-terminus regulates fast synaptic vesicle fusion and vesicle docking at the mammalian presynaptic active zone. eLife 6:e28412.

Martell JD, Deerinck TJ, Sancak Y, Poulos TL, Mootha VK, Sosinsky GE, Ellisman MH, Ting AY (2012) Engineered ascorbate peroxidase as a genetically encoded reporter for electron microscopy. Nat Biotechnol 30:1143-1148.

Martell JD, Deerinck TJ, Lam SS, Ellisman MH, Ting AY (2017) Electron microscopy using the genetically encoded APEX2 tag in cultured mammalian cells. Nat Protoc 12:1792-1816.

Misgeld T, Kerschensteiner M, Bareyre FM, Burgess RW, Lichtman JW (2007) Imaging axonal transport of mitochondria in vivo. Nat methods 4:559-561.

Montesinos MS, Chen Z, Young SM Jr (2011) pUNISHER: a high-level expression cassette for use with recombinant viral vectors for rapid and long term in vivo neuronal expression in the CNS. J Neurophysiol 106: 3230-3244.

Montesinos MS, Satterfield R, Young SM Jr (2016) Helper-dependent adenoviral vectors and their use for neuroscience applications. Methods Mol Biol 1474:73-90.

Morest DK (1968) The growth of synaptic endings in the mammalian brain: a study of the calyces of the trapezoid body. Z Anat Entwicklungsgesch 127:201-220.

Neher E (2015) Merits and limitations of vesicle pool models in view of heterogeneous populations of synaptic vesicles. Neuron 87:1131-1142.

Nguyen PV, Marin L, Atwood HL (1997) Synaptic physiology and mitochondrial function in crayfish tonic and phasic motor neurons. J Neurophysiol 78:281-294.

Obashi K, Okabe S (2013) Regulation of mitochondrial dynamics and distribution by synapse position and neuronal activity in the axon. Eur J Neurosci 38:2350-2363.

Perkins GA, Tjong J, Brown JM, Poquiz PH, Scott RT, Kolson DR, Ellisman MH, Spirou GA (2010) The micro-architecture of mitochondria at active zones: electron tomography reveals novel anchoring scaffolds and cristae structured for high-rate metabolism. J Neurosci 30:1015-1026.

Rodríguez-Contreras A, de Lange RP, Lucassen PJ, Borst JG (2006) Branching of calyceal afferents during postnatal development in the rat auditory brainstem. J Comp Neurol 496:214-228.

Rodríguez-Contreras A, van Hoeve JS, Habets RL, Locher H, Borst JG (2008) Dynamic development of the calyx of held synapse. Proc Natl Acad Sci U S A 105:5603-5608.

Rossi MJ, Pekkurnaz G (2019) Powerhouse of the mind: mitochondrial plasticity at the synapse. Curr Opin Neurobiol 57:149-155.

Rouder JN, Speckman PL, Sun D, Morey RD, Iverson G (2009) Bayesian tests for accepting and rejecting the null hypothesis. Psychon Bull Rev 16:225-237.

Rowland KC, Irby NK, Spirou GA (2000) Specialized synapse-associated structures within the calyx of held. J Neurosci 20:9135-9144.

Sätzler K, Söhl LF, Bollmann JH, Borst JG, Frotscher M, Sakmann B, Lübke JH (2002) Three-dimensional reconstruction of a calyx of held and its postsynaptic principal neuron in the medial nucleus of the trapezoid body. J Neurosci 22:10567-10579.

Saxton WM, Hollenbeck PJ (2012) The axonal transport of mitochondria. J Cell Sci 125:2095-2104.

Schindelin J, Arganda-Carreras I, Frise E, Kaynig V, Longair M, Pietzsch T, Preibisch S, Rueden C, Saalfeld S, Schmid B, Tinevez JY, White DJ, Hartenstein V, Eliceiri K, Tomancak P, Cardona A (2012) Fiji: an opensource platform for biological-image analysis. Nat Methods 9:676-682.

Stasiak A, Sayles M, Winter IM (2018) Perfidious synaptic transmission in the guinea-pig auditory brainstem. PloS One 13:e0203712.

Stirling JW, Graff PS (1995) Antigen unmasking for immunoelectron microscopy: labeling is improved by treating with sodium ethoxide or sodium metaperiodate, then heating on retrieval medium. J Histochem Cytochem 43:115-123.

Taschenberger H, von Gersdorff H (2000) Fine-tuning an auditory synapse for speed and fidelity: developmental changes in presynaptic waveform, EPSC kinetics, and synaptic plasticity. J Neurosci 20:9162-9173.

Taschenberger H, Leão RM, Rowland KC, Spirou GA, von Gersdorff H 
(2002) Optimizing synaptic architecture and efficiency for highfrequency transmission. Neuron 36:1127-1143.

Traynelis SF (1998) Software-based correction of single compartment series resistance errors. J Neurosci Methods 86:25-34.

Tritsch NX, Bergles DE (2010) Developmental regulation of spontaneous activity in the mammalian cochlea. J Neurosci 30:1539-1550.

Verstreken P, Ly CV, Venken KJ, Koh TW, Zhou Y, Bellen HJ (2005) Synaptic mitochondria are critical for mobilization of reserve pool vesicles at Drosophila neuromuscular junctions. Neuron 47:365-378.

Vos M, Lauwers E, Verstreken P (2010) Synaptic mitochondria in synaptic transmission and organization of vesicle pools in health and disease. Front Synaptic Neurosci 2:139.

Wang LY, Neher E, Taschenberger H (2008) Synaptic vesicles in mature calyx of held synapses sense higher nanodomain calcium concentrations during action potential-evoked glutamate release. J Neurosci 28:1445014458.

Wang T, de Kok L, Willemsen R, Elgersma Y, Borst JG (2015) In vivo synaptic transmission and morphology in mouse models of tuberous scle- rosis, Fragile X syndrome, neurofibromatosis type 1, and Costello syndrome. Front Cell Neurosci 9:234.

Wimmer VC, Horstmann H, Groh A, Kuner T (2006) Donut-like topology of synaptic vesicles with a central cluster of mitochondria wrapped into membrane protrusions: a novel structure-function module of the adult calyx of held. J Neurosci 26:109-116.

Xiao L, Michalski N, Kronander E, Gjoni E, Genoud C, Knott G, Schneggenburger R (2013) BMP signaling specifies the development of a large and fast CNS synapse. Nat Neurosci 16:856-864.

Xu J, Berret E, Kim JH (2017) Activity-dependent formation and location of voltage-gated sodium channel clusters at a CNS nerve terminal during postnatal development. J Neurophysiol 117:582-593.

Yang YM, Fedchyshyn MJ, Grande G, Aitoubah J, Tsang CW, Xie H, Ackerley CA, Trimble WS, Wang LY (2010) Septins regulate developmental switching from microdomain to nanodomain coupling of $\mathrm{Ca}^{2+}$ influx to neurotransmitter release at a central synapse. Neuron 67:100-115.

Yu WM, Goodrich LV (2014) Morphological and physiological development of auditory synapses. Hear Res 311:3-16. 